\title{
A Mechanistically Credible, Poleward Shift in Warm-Season Precipitation Projected for the U.S. Southern Great Plains?
}

\author{
MELISSA S. BUKOVSKY AND RACHEL R. MCCRARY \\ National Center for Atmospheric Research, Boulder, Colorado \\ ANJI SETH \\ University of Connecticut, Storrs, Connecticut \\ LINDA O. MEARNS \\ National Center for Atmospheric Research, Boulder, Colorado
}

(Manuscript received 18 April 2016, in final form 9 May 2017)

\begin{abstract}
Global and regional climate model ensembles project that the annual cycle of rainfall over the southern Great Plains (SGP) will amplify by midcentury. Models indicate that warm-season precipitation will increase during the early spring wet season but shift north earlier in the season, intensifying late summer drying. Regional climate models (RCMs) project larger precipitation changes than their global climate model (GCM) counterparts. This is particularly true during the dry season. The credibility of the RCM projections is established by exploring the larger-scale dynamical and local land-atmosphere feedback processes that drive future changes in the simulations, that is, the responsible mechanisms or processes. In this case, it is found that out of $12 \mathrm{RCM}$ simulations produced for the North American Regional Climate Change Assessment Program (NARCCAP), the majority are mechanistically credible and consistent in the mean changes they are producing in the SGP. Both larger-scale dynamical processes and local land-atmosphere feedbacks drive an earlier end to the spring wet period and deepening of the summer dry season in the SGP. The midlatitude upper-level jet shifts northward, the monsoon anticyclone expands, and the Great Plains low-level jet increases in strength, all supporting a poleward shift in precipitation in the future. This dynamically forced shift causes land-atmosphere coupling to strengthen earlier in the summer, which in turn leads to earlier evaporation of soil moisture in the summer, resulting in extreme drying later in the summer.
\end{abstract}

\section{Introduction}

The purpose of this paper is to assess the dynamical, process-level credibility of the regional climate model (RCM) projections from the North American Regional Climate Change Assessment Program (NARCCAP) in the context of CMIP3 and CMIP5 for warm-season precipitation in the southern Great Plains (SGP), as defined here in Fig. 1. In assessing the degree of "credibility" in the projections (as in, e.g., Brekke et al. 2008;

Supplemental information related to this paper is available at the Journals Online website: https://dx.doi.org/10.1175/ JCLI-D-16-0316.s1.

Corresponding author: Melissa S. Bukovsky, bukovsky@ucar. edu
Koutsoyiannis et al. 2008; Barsugli et al. 2013; Bukovsky et al. 2013, 2015), we are looking for relative model accuracy in simulating twentieth-century climate, evaluating the effect of biases on projections of twenty-first-century climate, and searching for projections that are physically and/or mechanistically plausible in a warming climate. The latter part of this definition is important because we are not just assessing the technical adequacy of the historical simulations to establish their credibility in producing precipitation projections. We believe that for projection credibility, historical fidelity is necessary but not automatically sufficient. Therefore, we are including the explanation of credibility given in Christensen et al. (2013, p. 1255) in our characterization: "[c]redibility in regional climate change projections is increased if it is possible to find key drivers of the change that are known to be well-simulated and well-projected by climate 


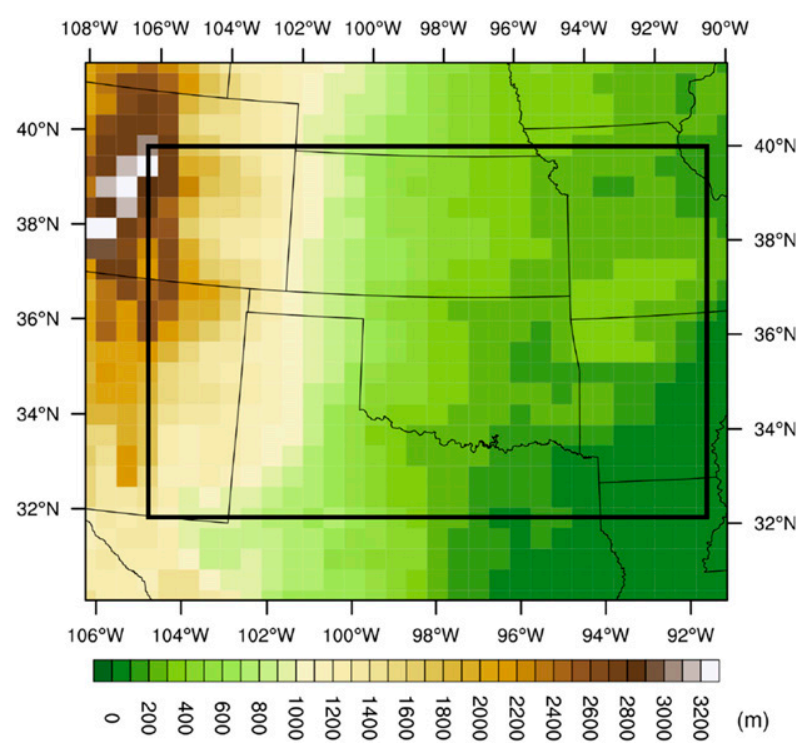

FIG. 1. Surface elevation (m) from HRM3 with the SGP region specified for this analysis outlined in black.

models." Thus, in addition to historical accuracy, we are examining the mechanisms behind the precipitation changes, assessing whether they are well simulated and whether they are changing in a manner that makes sense in a warming climate.

Partly, we focus on the SGP in this study as it is often neglected in studies of projections for central U.S. precipitation, which have often emphasized the central and northern Great Plains and Midwest, even if including the SGP (e.g., Liang et al. 2006; Bukovsky and Karoly 2011; Harding and Snyder 2014).

Generally, projections for warm-season mean precipitation changes in the future remain unclear when considering the whole of the central United States (e.g., Christensen et al. 2013; Harding and Snyder 2014; Mearns et al. 2014). This is partly because global climate models (GCMs) fail to realistically simulate the region's characteristic heavy, convective precipitation events, because of their generally coarser spatial resolution and use of convective parameterizations (e.g., Duffy et al. 2003; Dai 2006; Moncrieff and Liu 2006; Patricola and Cook 2013b; Harding et al. 2013). RCMs have been shown to better simulate central U.S. precipitation compared to GCMs, even when using convective parameterizations (e.g., Liang et al. 2006; Bukovsky and Karoly 2011; Harding et al. 2013), likely resulting from a combination of higher resolution and model configurations specifically tailored to the region. However, over the full central U.S. region, future projections of mean precipitation from RCMs remain uncertain, as RCM studies have not focused on the same domain, season, or emission scenarios. Also, RCM ensemble sizes (in terms of RCMs and the GCM drivers) are smaller than the CMIP3 and CMIP5 GCM ensembles and do not fully cover the range of model uncertainties (Mearns et al. 2014). Therefore, in this study, we will focus on changes in mean precipitation.

The results of Mearns et al. (2013) suggested that projections for the SGP may not be as uncertain as the projections for the entire central United States and initially motivated the present analysis. In Fig. 2 of Mearns et al. (2013), there is a strong signal for a decrease $(10 \%-$ $20 \%$ ) in June-August (JJA) mean precipitation by midcentury in the NARCCAP ensemble mean over the SGP as defined here with strong consensus among the RCMs. This signal is stronger in the RCMs than from a 17-GCM ensemble of simulations from phase 3 of the Coupled Model Intercomparison Project (CMIP3) $(5 \%-10 \%)$ and the four-member ensemble of NARCCAP driving GCMs $(5 \%-10 \%)$. It was hypothesized in Mearns et al. (2013) that the deeper drying in the RCMs may be due to an enhancement of land-atmosphere coupling in the future, based on early results from Dirmeyer et al. (2012), who showed that landatmosphere coupling may intensify in the future. As part of the present study, we examine this hypothesis further, as well as other mechanisms for precipitation change. JJA is not the ideal season for fully examining changes in warm-season precipitation in the SGP though, as there is an earlier spring peak in warm-season precipitation that occurs in this area (see the regional overview in section 2a). Therefore, we expand the analysis here to examine the causes of the precipitation projections from April through August.

The potential for drying in the SGP in JJA by midcentury was corroborated in Patricola and Cook (2013b) with wetter conditions in April and May in the seven NARCCAP RCMs used and one additional $30-\mathrm{km}$ horizontal-resolution RCM simulation that was completed using a unique modeling approach. The results from 15 CMIP3 GCMs used in Patricola and Cook (2013b) were less conclusive, except in July-August, when they agreed on drying. The results from the one additional RCM simulation were further analyzed in Patricola and Cook (2013a), and the changes in precipitation from that run were shown to be related to changes in moisture transport, resulting from changes in the Great Plains low-level jet (GPLLJ). It was also suggested that the drying that persists into August and September is related to a reduction in soil moisture and land-atmosphere feedback. The credibility of these results, however, relies to some degree on the agreement of the projection from their one $30-\mathrm{km}$ RCM projection with the NARCCAP projections, the latter of which did not first undergo the same level of scrutiny. Here, we 
intend to assess the credibility of the NARCCAP projections themselves, which would then, in a sense, add to the credibility of the Patricola and Cook (2013b) projections.

We know from Mearns et al. (2013) that there is a strong model consensus for mean drying in the SGP in JJA. In section 3 we will show that a marked consensus for mean change in precipitation extends from April through August (noting that the mean change switches sign through the season). To assess the credibility of this consensus, in section 4 we examine the mechanisms driving the changes in mean precipitation and establish physical arguments for their plausibility in a warming climate [as argued for in Held and Soden (2006)]. We also delve into details of the individual simulations, but only where necessary to support their individual credibility and explain model disagreements. In this analysis, the mechanisms driving the mean precipitation changes in the SGP that we examine include the monsoon anticyclone, the upper-level jet, the GPLLJ, and landatmosphere coupling.

To conclude our analysis, we present projections for additional characteristics of precipitation that complement our examination of mean precipitation change (e.g., changes in frequency, intensity, and convective severity) in section 5 . While this is not the primary focus of our analysis, these characteristics warrant further study owing to their importance, particularly in this region and season, where most precipitation is produced during convective events (Changnon 2001). Extremes have been well studied in other RCM and GCM projections for the central United States and are less uncertain as they are tied to physically plausible, clear changes in water vapor content in a warming environment and a future increase in the strength of the GPLLJ (Cook et al. 2008; Weaver et al. 2009; Bukovsky and Karoly 2011; Li et al. 2011; Wehner 2013; Harding and Snyder 2014; Mahoney et al. 2013).

\section{Background and methodology}

\section{a. Region overview}

Our analysis focuses on the southern Great Plains (SGP), defined here as approximately $32^{\circ}-40^{\circ} \mathrm{N}, 91^{\circ}-$ $105^{\circ} \mathrm{W}$, as in Fig. 1. All calculations are performed over this region unless otherwise specified.

In the SGP, springtime instability from surface heating combined with moisture from the Gulf of Mexico and numerous disturbances forcing ascent contribute to a peak in annual precipitation in May over most of the region. Thunderstorms produce most of the precipitation in this region (60\%-70\%; Changnon 2001), and the peak in May also corresponds with a peak in severe weather (Doswell et al. 2005). SGP precipitation during this spring wet period from April to June (AMJ) is often coincident with baroclinic waves and therefore much more dynamically forced than warm-season precipitation in the central and northern plains later in the season, which occurs under weaker forcing scenarios (Johns 1993; Carbone et al. 2002; Tuttle and Davis 2006). The more dynamic forcing suggests that models may do a better job simulating the convection. These baroclinic systems also play a role in bringing low-level moisture to the region, east of the waves; however, the GPLLJ is responsible for most of the low-level moisture advected into the SGP (Helfand and Schubert 1995). Additionally, during spring, upward motion over the SGP is enhanced by the position of the upper-level jet, as the divergent left exit region is located over the SGP on average (Wang and Chen 2009).

In June precipitation starts to decrease leading to a relative dry period in July and August (JA) after the spring convective period, except over the high plains in the very western part of this region, which have their peak in thunderstorm frequency during JA (Tucker and Li 2009). The dry period sets in as the warm-season precipitation corridor moves northward (Ashley et al. 2003; Wang and Chen 2009). The northward movement of the precipitation corridor, as well as the active suppression of convection during JA in the SGP, occurs in response to several related physical mechanisms. Enhanced heating of the troposphere over land stabilizes the atmosphere and strengthens the monsoon anticyclone or "high" at mid-to-upper levels and shifts it northward. The upper-level jet also shifts northward in response, positioning large-scale convergence over the area as a result (leading to broad subsidence).

The monsoon high is present in the mid-to-upper troposphere and is the result of the enhanced heating of the atmosphere over land, especially the elevated terrain of Mexico and the western United States (Higgins et al. 1997, 1999). In June, the monsoon anticyclone migrates northward and is generally positioned over the southwestern United States on average in July and August. This northward migration of the anticyclone effectively suppresses convection over the SGP, essentially concluding the late-spring wet period while initiating the monsoon season in the southwestern United States.

The SGP is also recognized as a "hot spot" for landatmosphere coupling, as variations in soil moisture strongly influence surface fluxes, the overlying atmosphere, and local-regional climate (Koster et al. 2004, 2006). While precipitation always has a direct influence on soil moisture, in regions where land-atmosphere coupling is strong surface soil moisture can also 
TABLE 1. GCMs and RCMs used in NARCCAP, their identifying acronyms used herein (RCM acronyms are as used in the NARCCAP model archive), and relevant references. For the GCMs, horizontal resolution and CMIP3 archive ensemble member number are also listed.

\begin{tabular}{|c|c|c|}
\hline Acronym & Model & References \\
\hline \multicolumn{3}{|l|}{ GCM } \\
\hline CCSM & $\begin{array}{l}\text { NCAR Community Climate System Model, version } 3 \text { (CCSM3), } \\
1.4^{\circ} \times 1.4^{\circ}(\mathrm{T} 85) \text {, run } 5\end{array}$ & Collins et al. (2006) \\
\hline CGCM & $\begin{array}{l}\text { Third Generation Canadian Coupled Global Climate Model, } \\
\text { version } 3(\mathrm{CGCM} 3), 1.9^{\circ} \times 1.9^{\circ}(\mathrm{T} 47) \text {, run } 4\end{array}$ & Flato et al. (2000) \\
\hline GFDL & $\begin{array}{l}\text { GFDL Climate Model, version } 2.0 \text { (GFDL CM2.0), } \\
2.0^{\circ} \times 2.5^{\circ} \text {, run } 2\end{array}$ & Anderson et al. (2004) \\
\hline HADCM & $\begin{array}{l}\text { Hadley Centre Coupled Model, version } 3 \text { (HadCM3), } \\
2.5^{\circ} \times 3.75^{\circ} \text {; this run is not part of the CMIP } 3 \text { archive }\end{array}$ & Gordon et al. (2000) and Pope et al. (2000) \\
\hline \multicolumn{3}{|l|}{$\mathrm{RCM}$} \\
\hline CRCM & Canadian RCM & Caya and Laprise (1999) \\
\hline ECP2 & $\begin{array}{l}\text { Experimental Climate Prediction Center's version of the } \\
\text { Regional Spectral Model }\end{array}$ & Juang et al. (1997) \\
\hline HRM3 & Third-generation Hadley Centre RCM & Jones et al. (2003) \\
\hline MM5I & $\begin{array}{l}\text { Fifth-generation Pennsylvania State University-National } \\
\text { Center for Atmospheric Research (NCAR) Mesoscale Model }\end{array}$ & Grell et al. (1993) \\
\hline RCM3 & International Centre for Theoretical Physics RCM, version 3 & $\begin{array}{l}\text { Giorgi et al. (1993a), Giorgi et al. (1993b), } \\
\text { and Pal et al. (2007) }\end{array}$ \\
\hline WRFG & Weather Research and Forecasting Model & Skamarock et al. (2005) \\
\hline
\end{tabular}

influence precipitation by regulating evapotranspiration from the surface (i.e., precipitation recycling). Additionally, in moisture-limited regimes like the SGP during summer soil moisture variations also affect sensible heat fluxes, which can impact precipitation indirectly by affecting boundary layer characteristics and atmospheric stability.

During April, May, and early June, large-scale moisture transport ahead of baroclinic waves and from the GPLLJ fuels precipitation. Soil moisture tends to increase, as gains from precipitation exceed losses via evaporation. As precipitation decreases and the dry season sets in later in June, evaporation becomes a local source of moisture. During late June, July, and early August, evaporation exceeds precipitation, and soil moisture conditions dry. During this period, soil moisture conditions can exhibit significant control on the overlying atmosphere. During the early part of the dry season, the SGP acts as a net exporter of moisture, where SGP regional evaporated moisture is transported to other regions (Roads et al. 1994). By late August, at the end of the dry season, precipitation and evaporation are nearly balanced, as the buildup of soil moisture during the spring has been lost to the atmosphere during the drier part of summer.

\section{b. Models}

As a part of NARCCAP, six RCMs were used to downscale four GCMs to $50 \mathrm{~km}$, with 12 total simulations, all of which are included in this study (Mearns et al. 2007). The RCMs and GCMs are listed in Table 1 , while the simulation combinations are listed in Table 2. For more information on these simulations, see Mearns et al. (2012). Herein, when referring to a simulation, the forcing simulation (typically the GCM) is listed second in lowercase (e.g., CRCM-cgcm); otherwise, all acronyms are in uppercase. Three of the four driving GCMs used in NARCCAP are part of the CMIP3 dataset (GFDL, CCSM, and CGCM), while the fourth was produced specifically for NARCCAP (HADCM) but performed similarly to the version of the model used for CMIP3 simulations (Mearns et al. 2013). Future projections are based on the Special Report on Emissions Scenarios (SRES; Nakićenović et al. 2000) A2 scenario. Additionally, while all simulations were performed at the same spatial resolution, each model uses a distinct map projection; therefore, for ensemble calculations the simulations were first interpolated to a common $0.5^{\circ} \times$ $0.5^{\circ}$ grid. Other calculations are performed on the

TABLE 2. NARCCAP RCM-GCM simulation combinations marked with an $\mathrm{X}$.

\begin{tabular}{lcccc}
\hline & \multicolumn{4}{c}{ GCM } \\
\cline { 2 - 5 } RCM & CCSM & CGCM & GFDL & HADCM \\
\hline CRCM & $\mathrm{X}$ & $\mathrm{X}$ & $\mathrm{X}$ & $\mathrm{X}$ \\
ECP2 & & & $\mathrm{X}$ & $\mathrm{X}$ \\
HRM3 & & & & $\mathrm{X}$ \\
MM5I & $\mathrm{X}$ & & $\mathrm{X}$ & \\
RCM3 & & $\mathrm{X}$ & & \\
WRFG & $\mathrm{X}$ & $\mathrm{X}$ & & \\
\hline
\end{tabular}


models' native grids. Simulations for the baseline/ historical period span 1971-99, future simulations span 2041-69, and all analyses conducted herein are performed for these periods unless otherwise specified. A few variables used in this study are not available from certain simulations. Land surface variables such as soil moisture and surface turbulent heat fluxes are not available from the HADCM. Similarly, variables above surface level are not available from the ECP2 GCMdriven simulations, and vertical motion is not available from several simulations (as noted later in relevant figures).

For comparison purposes, we also include projections of precipitation from simulations produced for CMIP3 and CMIP5. Single realizations from 17 CMIP3 simulations and 35 CMIP5 simulations are used, and the models are listed in Table S.1 of the supplemental material for reference. For the future projections, the CMIP3 simulations used are based on the SRES A2 scenario and the CMIP5 simulations are based on representative concentration pathway 8.5 (RCP8.5; Moss et al. 2008). For the purposes of computing ensemble calculations only, all CMIP3 simulations were interpolated to a common $2^{\circ} \times 2^{\circ}$ grid and all CMIP5 simulations to a $1^{\circ} \times 1^{\circ}$ grid.

\section{c. Other datasets}

We verify precipitation from the simulations against the Climate Predication Center's (CPC) unified gaugebased analysis of daily precipitation over the continental United States (CONUS). The precipitation dataset (hereafter referred to as CPC) is on a $0.25^{\circ} \times 0.25^{\circ}$ latitude-longitude grid. For direct statistical comparison with the simulations (e.g., in spatial correlations), it is interpolated to the resolution of a given model (RCM or GCM) using the "area_hi2lores_Wrap" function available in the NCAR Command Language (NCL 2016). The CPC dataset is available daily from 1948 to 2006, covering our full baseline analysis period.

The 32-km-resolution North American Regional Reanalysis (NARR; Mesinger et al. 2006) is used to verify upper-level fields (e.g., geopotential height and winds) from the simulations.

\section{d. Methods}

\section{1) SignificAnce testing And AgREement}

Statistical significance of the climate projections is tested at the 0.1 level using bootstrapping with bias correction and acceleration unless otherwise noted [von Storch and Zwiers (1999) and Efron and Tibshirani (1993), as described in more detail in Bukovsky and Karoly (2011)]. For monthly differences, 5000 bootstrap samples are used, and for multimonth differences 1000 samples are used. As applied, this method essentially shows where differences are outside of the range of variability in the years used in the analysis with $90 \%$ confidence.

In section 3, Fig. 2, we present ensemble mean precipitation change and adjust the intensity of the color scale using the percent of simulations that agree on the sign of the ensemble mean change. The percent in agreement is scaled by the likelihood of agreement and calculated using the kappa statistic (Cohen 1960; Fleiss 1971). This more accurately reflects the percent of agreement across ensembles of different sizes, as it adjusts agreement to account for the possibility of agreement by chance. This measure of agreement is often used when examining ratings from surveys, in which case the raters are synonymous with the simulations here. Agreement using the kappa statistic $K$ is simply defined as the degree to which the observed agreement across ensemble members exceeds that which would be expected if the agreement were random. The $K$ is the degree of agreement actually achieved above chance (Po - Pc) divided by the degree of agreement possible above chance $(1-\mathrm{Pc})$, where Po is the observed agreement in the ensemble, and $\mathrm{Pc}$ is the probability of that number agreeing by chance. The Pc is calculated as if a coin were being flipped, as there are only two possibilities here as well (agreement on positive change or agreement on negative change). That is, $\mathrm{Pc}=N ! /\left[n !(N-n) ! 2^{N}\right]$, where $N$ is the number of simulations in agreement and $n$ is the total number of simulations in the ensemble. It should be noted that using $K$ to scale agreement by likelihood does assume that each simulation is an independent sample, which is likely not the case, particularly for the NARCCAP simulations using the same forcing GCMs; however, assessing degree of independence is outside the scope of this project.

\section{2) CAPE, CIN, AND SHEAR CALCULATIONS}

In section 5, we examine future changes in convective environments in seven of the NARCCAP simulations. These seven simulations have the necessary variables for calculating convective available potential energy (CAPE) and convective inhibition (CIN). These are the CRCMccsm, CRCM-cgcm, MM5I-ccsm, MM5I-hadcm, HRM3hadcm, WRFG-ccsm, and WRFG-cgem.

Full-column atmospheric variables from NARCCAP are available on pressure levels every $25 \mathrm{hPa}$ from 1050 to $700 \mathrm{hPa}$ and every $50 \mathrm{hPa}$ from 650 to $50 \mathrm{hPa}$. Using the geopotential height field at the various pressure levels, the lowest (approximately) $3 \mathrm{~km}$ of the atmosphere is divided up into 500-m depth layers. Average equivalent potential temperature $\theta_{e}$ is calculated for 


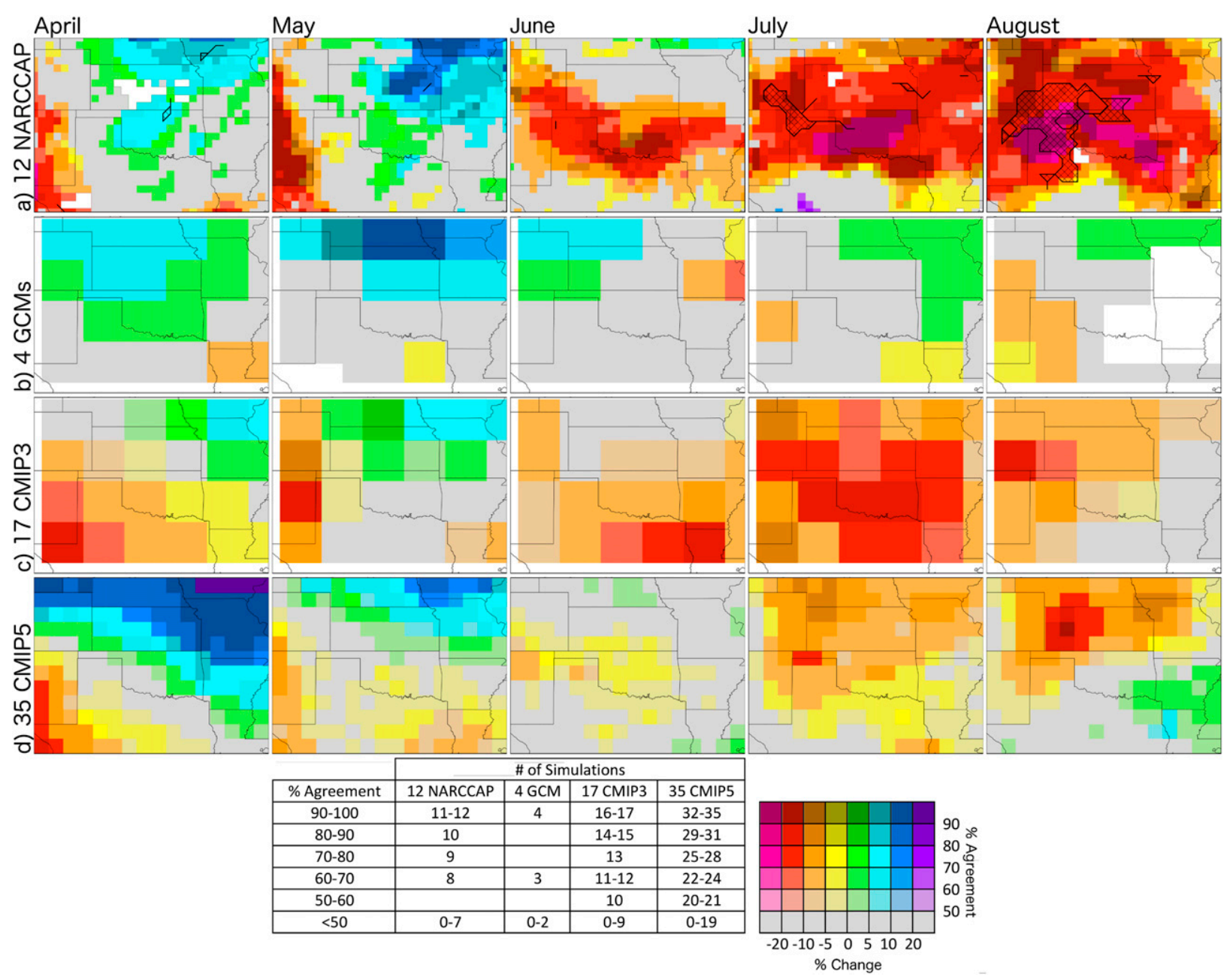

FIG. 2. Monthly mean precipitation change (\%) from the baseline period for (a) the 12-simulation NARCCAP ensemble, (b) the 4 GCMs used to force the NARCCAP suite, (c) 17 CMIP3 GCMs, and (d) 35 CMIP5 GCMs. Precipitation change is presented following methodology proposed by Tebaldi et al. (2011), with some modification: hatching indicates where more than $50 \%$ of the simulations show change that is significant at the 0.10 level (as determined by the Student's $t$ test) and where more than $75 \%$ of the simulations agree on the sign of change (thus, where the majority agree on significance and sign). White grid cells indicate where more than $50 \%$ of the simulations show change that is significant but also where $75 \%$ of the simulations or fewer agree on the sign of the change (thus indicating true disagreement and little information). Additionally, the percent of simulations that agree on the sign of the change is indicated by the color saturation and value (the vertical axis on the color bar). The percent agreement on sign of change is not a straight observed percent agreement but is scaled across the ensembles to adjust for differences in likelihood of agreement given differences in ensemble sizes [see section $2 \mathrm{~d}(1)$ for details]; therefore, a table is also provided at the bottom to indicate how many simulations are needed in each ensemble for a given level of agreement. To facilitate creating this ensemble average, all models were regridded to common grids in latitude/ longitude of $0.5^{\circ} \times 0.5^{\circ}$ for the RCMs, $2^{\circ} \times 2^{\circ}$ for the CMIP3 GCMs, and $1^{\circ} \times 1^{\circ}$ for the CMIP5 GCMs.

each layer, and $\mathrm{CAPE}^{1}$ and $\mathrm{CIN}$ are then calculated using the layer with the greatest $\theta_{e}$. CAPE is the accumulated positive buoyant energy from the level of free convection (LFC) to the equilibrium level, and CIN is

\footnotetext{
${ }^{1}$ The virtual temperature correction (Doswell and Rasmussen 1994) for these calculations is used, contrary to a statement made in Gensini et al. (2014), who used CAPE from the WRFG-ccsm provided by M. Bukovsky.
}

the accumulated negative buoyant energy from the parcel starting point to the LFC.

Wind shear is typically calculated over a layer from 0 to $6 \mathrm{~km}$ when examining convective environments (Rasmussen and Blanchard 1998). To avoid added interpolation error, we calculate shear for a layer from the surface to $500 \mathrm{hPa}$ instead; $500 \mathrm{hPa}$ is approximately $5.5 \mathrm{~km}$ above ground level for areas near sea level (COESA 1976).

Several severe thunderstorm environment parameters were calculated from these variables following Brooks 
et al. (2003), Trapp et al. (2007), and Gensini et al. (2014). These parameters include the frequency of CAPE exceeding $2000 \mathrm{~J} \mathrm{~kg}^{-1}$ ("high" CAPE) with or without CIN less than $100 \mathrm{~J} \mathrm{~kg}^{-1}$, the frequency of the 0 6-km shear exceeding $18 \mathrm{~m} \mathrm{~s}^{-1}$ with CAPE greater than $100 \mathrm{~J} \mathrm{~kg}^{-1}$ (so that it is only being examined in environments with convective potential), and the frequency of CAPE multiplied by shear greater than $10000 \mathrm{~J} \mathrm{~kg}^{-1} \mathrm{~m} \mathrm{~s}^{-1}$ (representing severe thunderstorm environment days) and greater than $20000 \mathrm{~J} \mathrm{~kg}^{-1} \mathrm{~m} \mathrm{~s}^{-1}$ (representing significant severe thunderstorm days).

\section{3) TERRESTRIAl COUPLING INDEX}

There are multiple metrics by which to examine the strength of the coupling between the land surface and the atmosphere in models. These range from complex physically based metrics such as precipitation recycling based on back trajectories (e.g., Brubaker et al. 2001; Dirmeyer and Brubaker 2007), the heated condensation framework (Tawfik and Dirmeyer 2014), and the convective triggering potential and humidity index (Findell and Eltahir 2003), to simpler statistical methods such as soil moisture memory (Delworth and Manabe 1988) or the terrestrial coupling index (TCI; Dirmeyer 2011). More complex methods might be worth exploring, but because of dataset restrictions and the large number of simulations we are examining, we chose to use the simpler TCI to explore the strength of the coupling between the soil moisture and latent heat flux (or evapotranspiration) in the NARCCAP RCMs and GCMs. The TCI is calculated as the correlation between soil moisture and latent heat flux multiplied by the standard deviation of the latent heat flux. In other words, the TCI is the change in latent heat flux given a typical (one standard deviation) change in soil moisture. As explained in Dirmeyer et al. (2013), a positive correlation between soil moisture and latent heat flux occurs when soil moisture is more limited than energy and soil moisture supply controls latent heat flux. The TCI will have the same sign as the correlation, but it is scaled by the magnitude of the changes in latent heat flux. Note that one would normally examine the upper layer of soil moisture, but only total column soil moisture is available from the NARCCAP RCMs, the depth of which varies by land surface model, so that is what is used here.

\section{Precipitation projections}

We first show monthly mean projected precipitation changes for April through August in Figs. 2a-d for the NARCCAP RCMs, their GCM drivers, and ensembles of CMIP3 and CMIP5 GCMs. These figures recap the Mearns et al. (2013) results and set the stage for our in-depth analysis of precipitation change in the SGP. As is evident in Figs. 2a-d, there is consensus across the NARCCAP, CMIP3, and CMIP5 ensembles for a northward shift in the convective corridor through the warm season. Toward the end of summer, this leaves the SGP with an enhanced dry season by midcentury, particularly in the NARCCAP RCMs. This shift also implies an earlier end to the spring wet period in the SGP, as precipitation in June tapers off earlier.

Focusing now on the NARCCAP RCMs, we see a similar story emerge from most of the individual RCMs (Fig. 3), although, as expected, there are differences among them. In almost all of the RCM simulations, except the HADCM-driven simulations and the ECP2gfdl, there is a transition from an increase in precipitation in April to an increase mostly in the northern half of the region and a decrease in the southern half in May, a similar pattern or widespread drying in June, and drying in July and August across most of the SGP. This pattern further supports the ensemble mean change and again suggests a northward shift in the region most favorable for convection and an earlier end to the spring wet period. Differences in the pattern of the changes across the RCMs show similarities by driving GCM. The CCSM-driven simulations have greater, more widespread increases in April and May, with stronger, more widespread decreases in June than the CGCM-driven simulations. Additionally, the pattern in two of the GFDL-driven simulations (HRM3 and RCM3) suggests a northward shift in mean precipitation starting in April. As mentioned, the HADCM-driven simulations do not agree with the other RCMs and show no coherent change patterns across the season. The reason for this departure will be explained in the next section, as we examine the credibility of the key drivers of these mean precipitation changes in the SGP in all of the RCMs.

Of the four NARCCAP driving GCMs, only GFDL has a similar projection story for monthly mean precipitation change as the NARCCAP and CMIP ensembles (Fig. 4). The CCSM projects strong increases in precipitation, the CGCM mostly projects insignificant increases, and the projections from HADCM are mixed and generally weak. In CCSM and CGCM, it is likely that the projected increase is the convective parameterization scheme's response to an increase in moisture and instability regardless of increased convective inhibition [as in projections to be shown in sections $4 \mathrm{~b}(1)$ and 5]. Not accounting for CIN is a known problem for convective parameterization schemes of the type used in both GCMs [in this case, Zhang and McFarlane (1995)] particularly in midlatitude, weakly forced, deep convective environments (Zhang 2002), as the SGP is later 

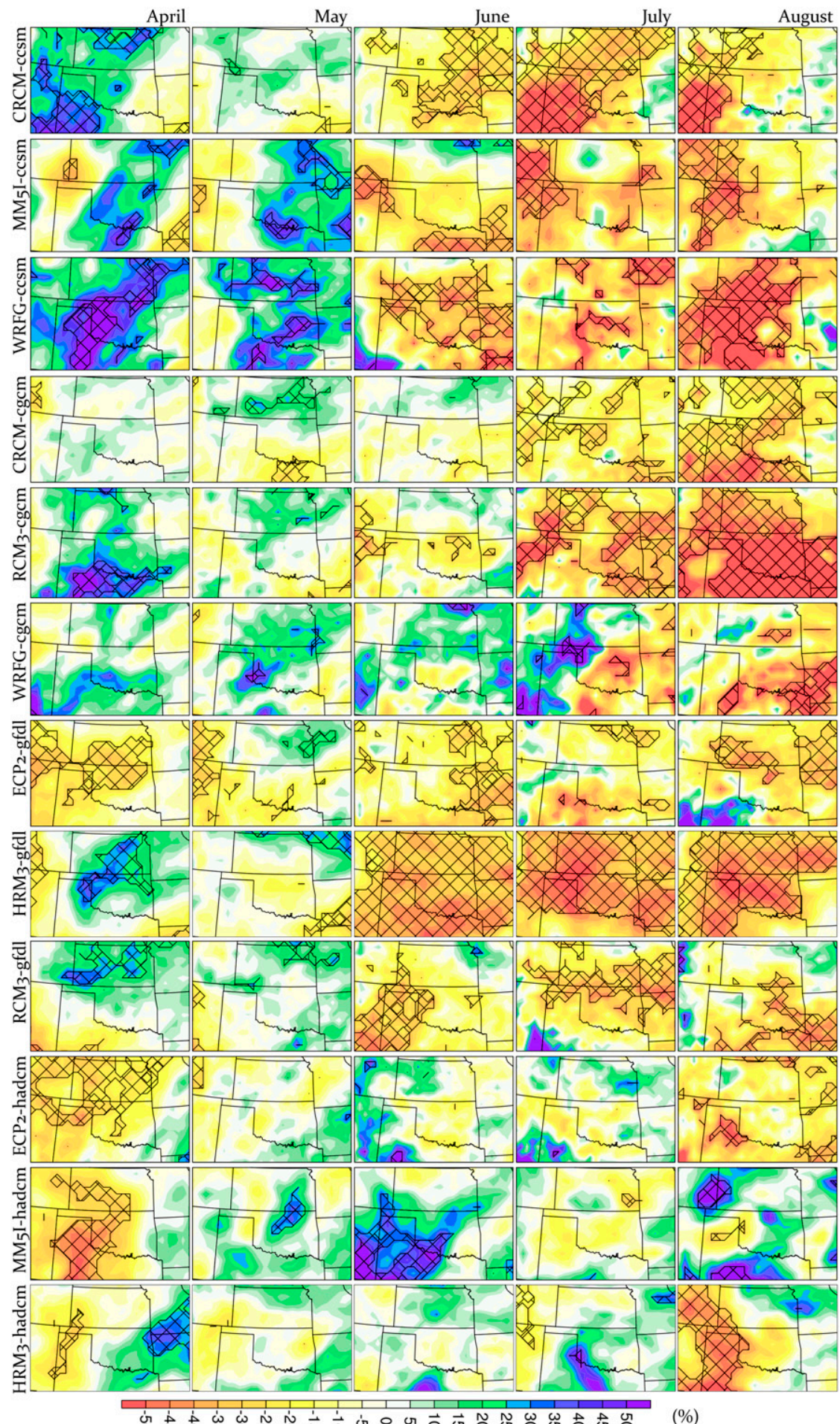

FIG. 3. Average monthly precipitation change (\%) from the baseline period for each NARCCAP simulation. Hatching indicates where the change is statistically significant at the 0.1 level. 


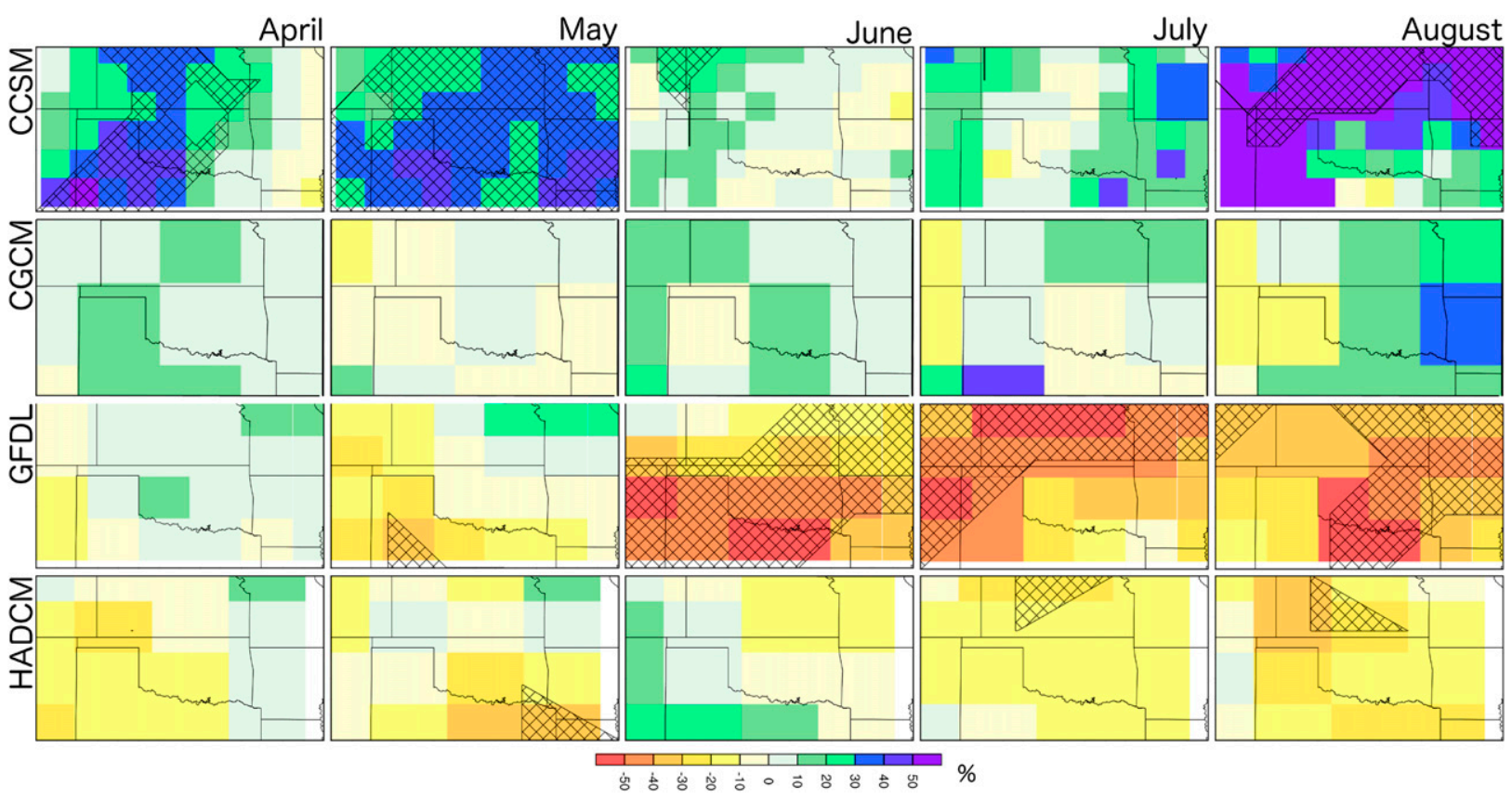

FIG. 4. As in Fig. 3, but for the NARCCAP GCM drivers.

in summer. In these schemes the convection is not suppressed by CIN and they tend to convect too easily to allow CAPE to build up in the environment [as illustrated by consistently low CAPE values in CCSM in Marsh et al. (2007)]. This is likely exacerbated in CCSM through an increase in terrestrial coupling in this model in July and August, as will be shown in section 4d.

\section{Credibility of precipitation projections}

\section{a. Baseline precipitation}

As compared with mean precipitation from the CPC, NARCCAP simulations produce precipitation that is distributed better spatially across the SGP than their driving GCMs (Figs. 5 and 6). As shown in Figs. 5 and 6, the RCMs better capture the west-east gradient of precipitation than the GCMs in AMJ and the southnorth gradient in JA. Pattern correlations comparing mean baseline precipitation to that of the CPC over the SGP region used in Fig. 2 support the better performance in the RCMs. The pattern correlation calculated on the models' native grids and averaged across all of the NARCCAP RCMs is $0.76(0.54)$ in AMJ (JA) and $0.46(0.42)$ averaged across the four driving GCMs. If we aggregate/interpolate all RCMs and GCMs to a $2^{\circ} \times 2^{\circ}$ grid, using local area averaging to "upscale" the RCMs, the RCM average pattern correlation is $0.73(0.50)$ in AMJ (JA) and 0.41 (0.37) averaged across the four driving GCMs. The similarity of the coarser grid calculation and the former native grid calculation indicates that the RCMs are producing more accurate large-scale, GCM-resolvable precipitation patterns. This added value is then likely due to the RCMs representing precipitation processes better on a larger-scale and not just because the RCMs and CPC contain finer-scale features that are unresolvable by the GCMs. Some of the RCMs are too dry in both parts of the warm season, particularly the CCSM- and CGCM-driven simulations. These biases mostly stem from GCM-inherited errors, particularly, a low humidity bias in the boundary conditions in both GCMs and a monsoon high that is too strong in the CCSM [as discussed in Bukovsky et al. (2013)]. Cold-biased sea surface temperatures in the CCSM also affect the amount of moisture flux from the Gulf of Mexico, adding to the dry bias in the RCMs it forces [as discussed in Bukovsky and Karoly (2011)].

The NARCCAP RCMs also realistically reproduce the annual cycle of precipitation for the SGP, with a peak occurring in May in most RCMs (Fig. 7), followed by a reduction in summer. The dry biases in the CGCMand CCSM-driven simulations, noted above, are particularly obvious in Fig. 7. Other biases include too early of a peak in the HADCM-driven simulations and too much precipitation in CCSM in June and the GFDLdriven simulations in winter-spring. The RCMs also show important differences from the GCM drivers; notably, those driven by CCSM are drier than observed and remain so through October, unlike CCSM, which is wetter than observed in June. The RCMs driven by GFDL tend to follow their driver more closely through 


\section{a) CCSM}

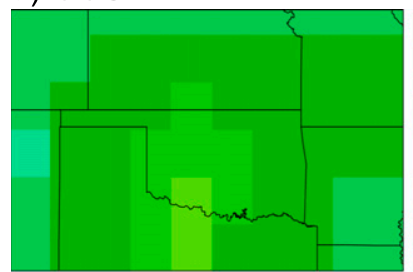

e) CGCM

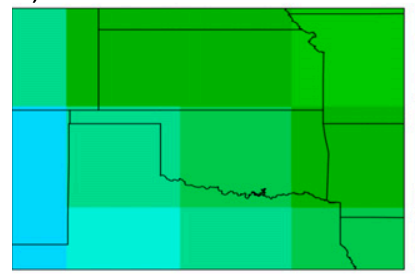

i) GFDL

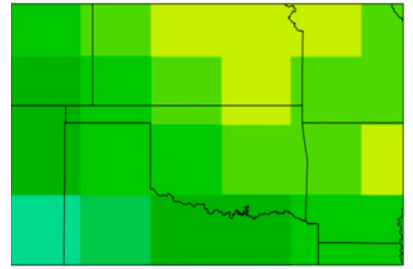

m) HADCM

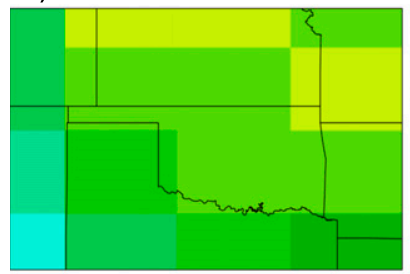

q) $\mathrm{CPC}$

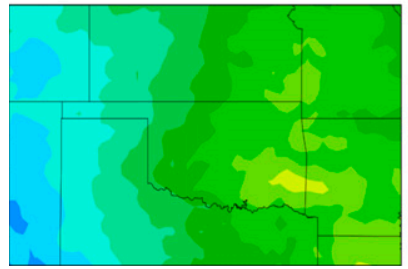

\section{b) CRCM-ccsm}

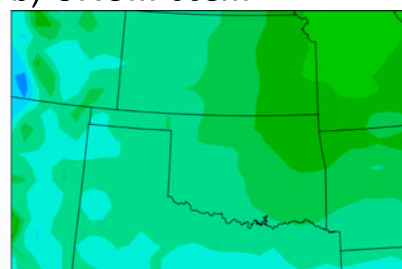

f) $\mathrm{CRCM}-\mathrm{cgcm}$

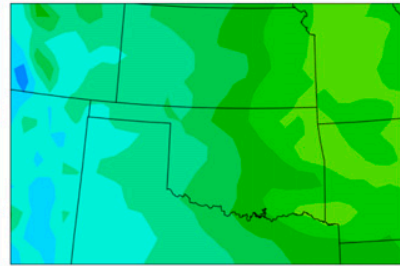

j) ECP2-gfdl

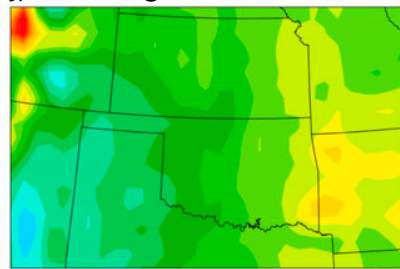

n) ECP2-hadcm

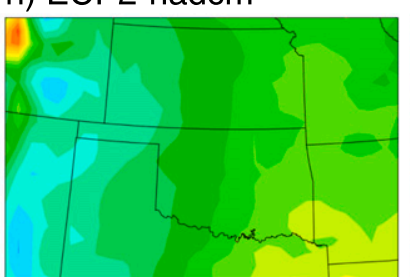

c) WRFG-ccsm

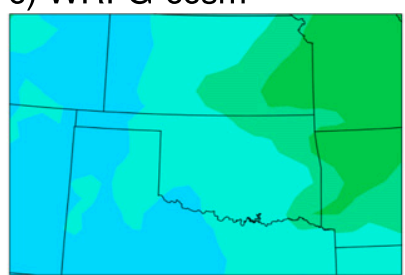

g) WRFG-cgcm

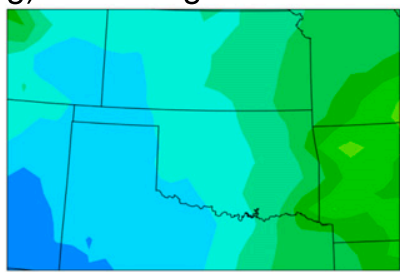

k)HRM3-gfdl

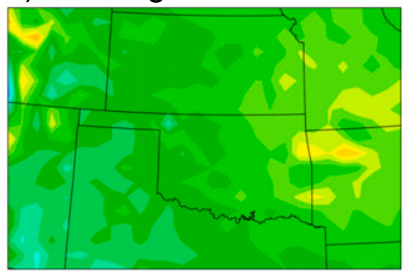

o) HRM3-hadcm

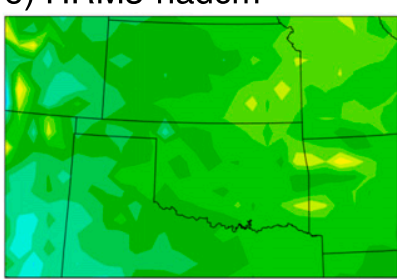

d) MM5I-ccsm

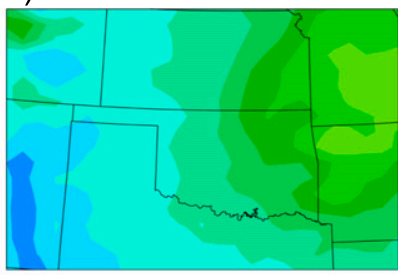

h) RCM3-cgcm

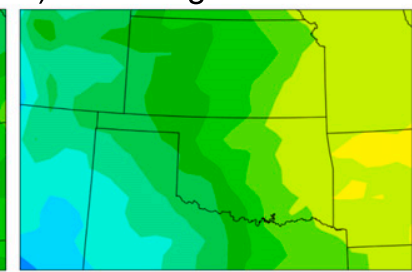

l) RCM3-gfdl

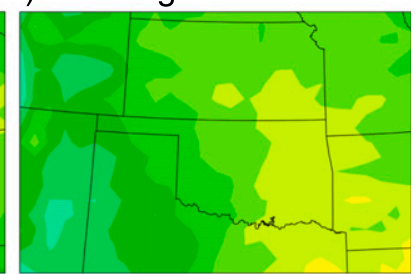

p) MM5I-hadcm

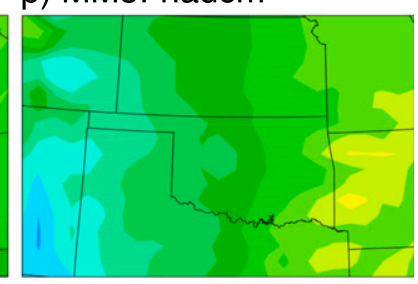

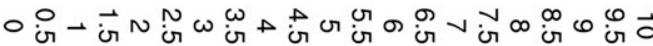

FIG. 5. AMJ average precipitation for the 1971-99 baseline period from the NARCCAP RCMs and their driving GCMs and the CPC precipitation dataset.

the season. The RCMs driven by HADCM also follow their driver closely and show similar monthly biases to the driving model.

\section{b. Physical mechanisms driving precipitation changes}

Changes in related physical processes or mechanisms driving the mean precipitation changes in the SGP are consistent across almost all of the NARCCAP simulations. This includes the expansion of the monsoon anticyclone, a projected northward shift in the midlatitude upper-level jet, and an increase in the strength of the GPLLJ. It is also likely that strong land surface coupling is contributing to the strength of the precipitation decrease in JA.

\section{1) Monsoon ANTICYCLONE}

One large-scale change supporting the ensemble mean change signal in SGP precipitation is the expansion of the monsoon high. In the future, the anticyclone is not projected to notably change its mean position by the NARCCAP RCMs, but it does intensify [as shown in Fig. 8 of Bukovsky et al. (2015) for JA], as is plausible in a warmer climate, particularly since the troposphere over land is warming faster than over the surrounding ocean 
a) $\operatorname{CCSM}$

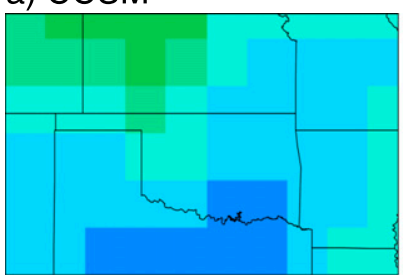

e) CGCM

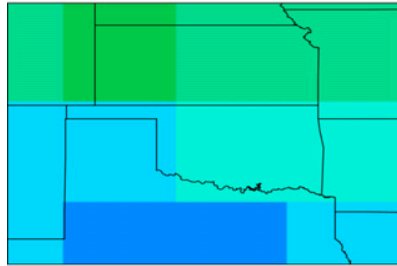

i) GFDL

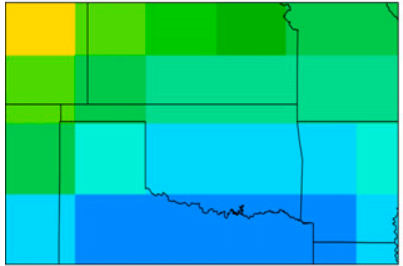

m) HADCM

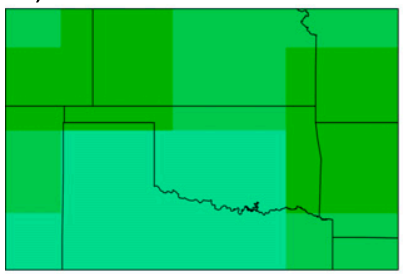

q) $\mathrm{CPC}$

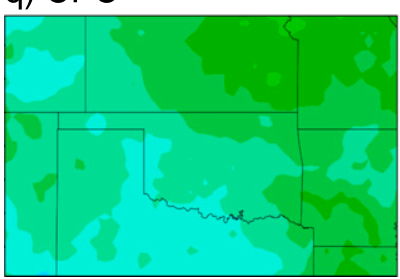

\section{b) CRCM-ccsm}

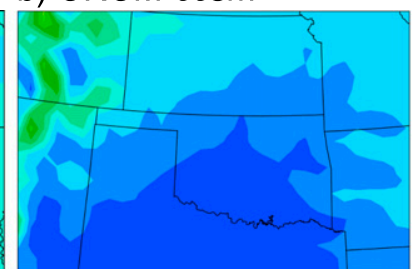

f) CRCM-cgcm

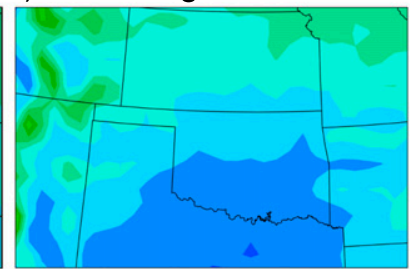

j) ECP2-gfdl

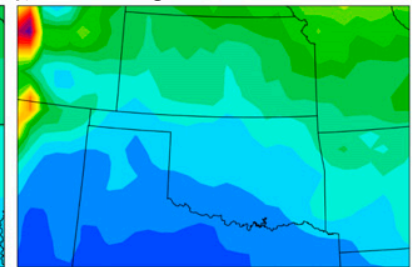

n) ECP2-hadcm

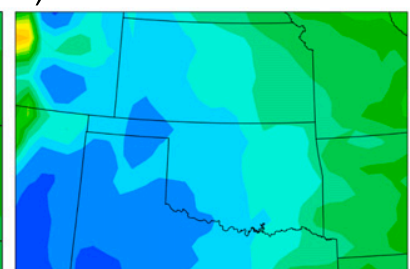

c) WRFG-ccsm

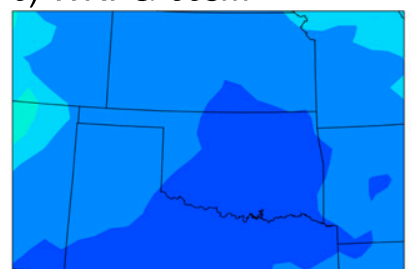

g) WRFG-cgcm

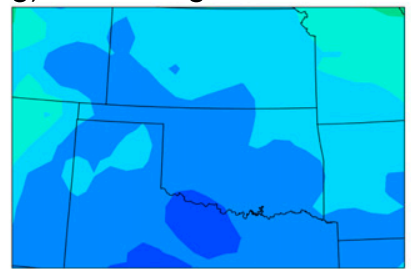

k)HRM3-gfdl

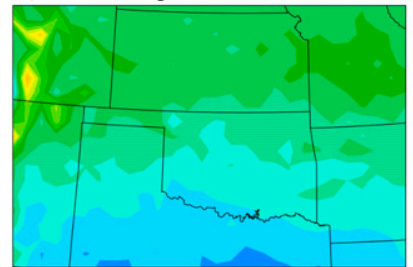

o) HRM3-hadcm

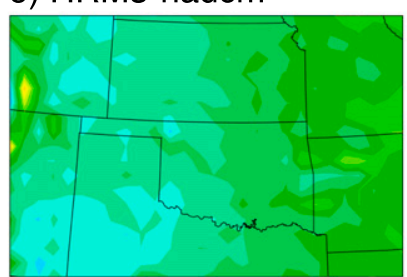

d) MM5I-ccsm

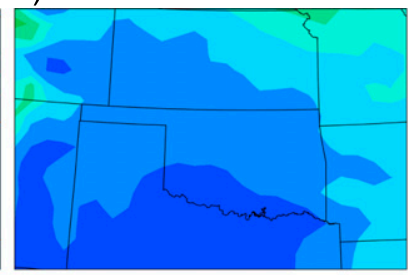

h) $\mathrm{RCM} 3-\mathrm{cgcm}$

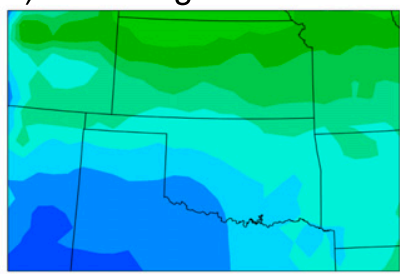

l) RCM3-gfdl

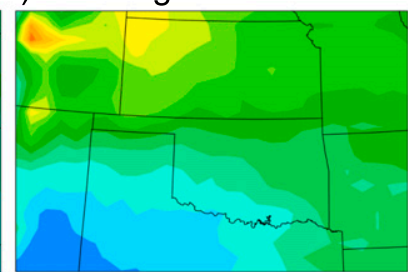

p) MM5I-hadcm

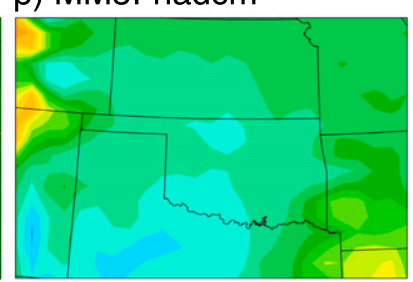

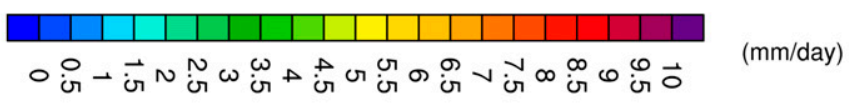

FIG. 6. As in Fig. 5, but for JA.

basins, and the heating of the troposphere over land relative to the oceans plays a strong role in the existence and evolution of the anticyclone to start. The basic broadening/ deepening of the high and the connected increase in midtropospheric temperatures would suppress convection earlier in summer over the SGP and act to further suppress convection later in the summer. That is, it would shift the region that is most favorable for convection away from the center of the high faster. This is because a stronger monsoon high could promote stronger, more widespread midtropospheric subsidence through increased upper-level convergence over the plains, and the increased midtroposphere temperatures would also further increase the stability of the atmosphere. These changes would, furthermore, lead to a stronger capping inversion layer of CIN (cap) for convection as a result. The increase in the strength of the cap is illustrated in Fig. 8 through the change in the frequency distribution of CIN. In interpreting Fig. 8, CIN less than $25 \mathrm{~J} \mathrm{~kg}^{-1}$ may be considered weak, from 25 to $50 \mathrm{~J} \mathrm{~kg}^{-1}$ moderate, from 50 to $100 \mathrm{~J} \mathrm{~kg}^{-1}$ strong, from 100 to $200 \mathrm{~J} \mathrm{~kg}^{-1}$ as very strong, and above $200 \mathrm{~J} \mathrm{~kg}^{-1}$ as an environment in which convection will generally not occur. By midcentury, there is a clear shift to more days with CIN greater than $100 \mathrm{~J} \mathrm{~kg}^{-1}$, particularly in AMJ (Fig. 8a), and a clear decrease in the 

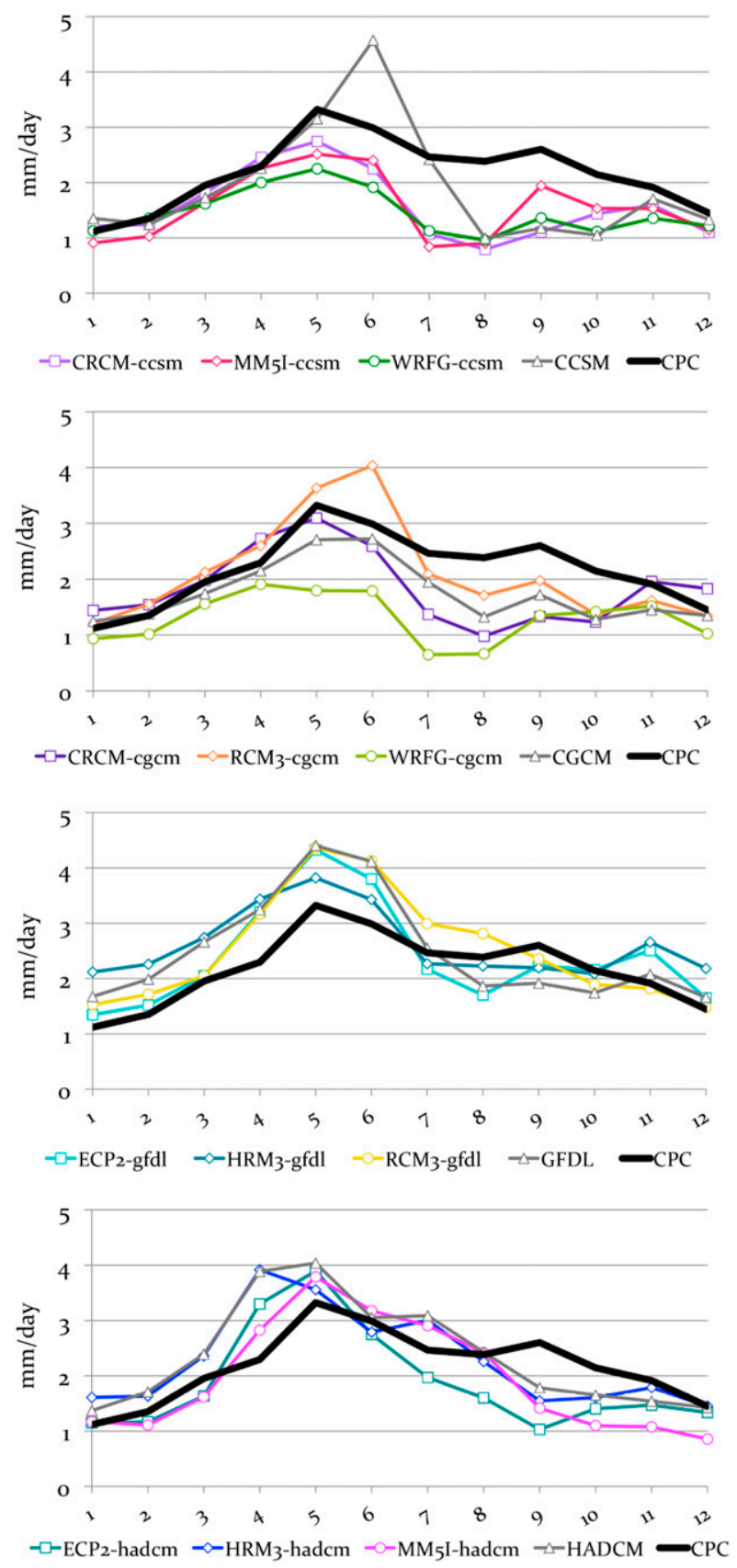

FIG. 7. The 1971-99 monthly average precipitation climatology from the GCM-driven RCMs and (top)-(bottom) their driving GCMs for the region outlined in Fig. 1. The 1971-99 average CPC precipitation is shown with the thick black line for reference.

number of days with weak to moderate CIN. Stronger forcing for convection would be necessary to maintain the baseline mean frequency of convection at a given location as a result, but the projected northward movement of the precipitation to a more conducive location toward the periphery of the anticyclone's influence and the increase in the number of dry days (discussed in section 5) in both AMJ and JA suggests that stronger forcing to maintain baseline frequencies is not occurring in the future.

The effect of the increased strength and the overall expansion of the monsoon high on projected precipitation here is similar to that shown by Lahmers et al. (2016) on North American monsoon system precipitation in the recent past on days when a transient inverted trough (IV) is present, but the effect is opposite in latitudinal influence. In the SGP, the expansion of the high is shifting future convection northward, and in the monsoon region, it has shifted IVs and their associated convection southward.

\section{2) UPPER-LEVEL JET}

Figure 9 and Fig. S.1 in the supplemental material illustrate a northward shift in the upper-level midlatitude jet for AMJ and JA, respectively. The shift is illustrated as decreasing westerlies in the southern part of the region (blue in Figs. 9 and S.1) and increasing westerlies in the northern part of it (red) and is present to some extent in all of the RCMs except the HADCM-driven simulations. In actuality, this would move the left-front quadrant of the jet, which is climatologically located over this region in May in baseline period observations, out of the SGP earlier in the summer. With it would move the dynamically forced upward motion that favors regional convection. This poleward shift, therefore, could be contributing further to the projected shift in precipitation. The northward shift is logical in the context of increased heating of the troposphere over the continent relative to the surrounding ocean basins and the resultant expansion of the monsoon high (as discussed in the previous subsection), as this would also cause the upper-level jet to move farther poleward during the season. The northward shift of the jet with anthropogenic warming has also been attributed to the widening of the tropical belt and is consistently seen in climate model projections and observations [e.g., as reviewed in Seidel et al. (2008) and Tandon et al. (2013)]. We therefore consider this aspect of the projections from the RCMs to be credible.

The notable outliers in Figs. 9 and S.1 are the HADCMdriven simulations. The changes in the upper-level jet do not match those from the other simulations because the jet in the HADCM and HADCM-driven simulations is not realistically simulated to start with over North America, so the changes do not represent changes to a realistically simulated phenomenon. It is too weak, positioned incorrectly, and does not evolve properly through the summer. This is illustrated using the HRM3-hadcm simulation in Fig. 10. This large-scale dynamical error is significant enough that we do not think the projections from these simulations are credible for this region and 


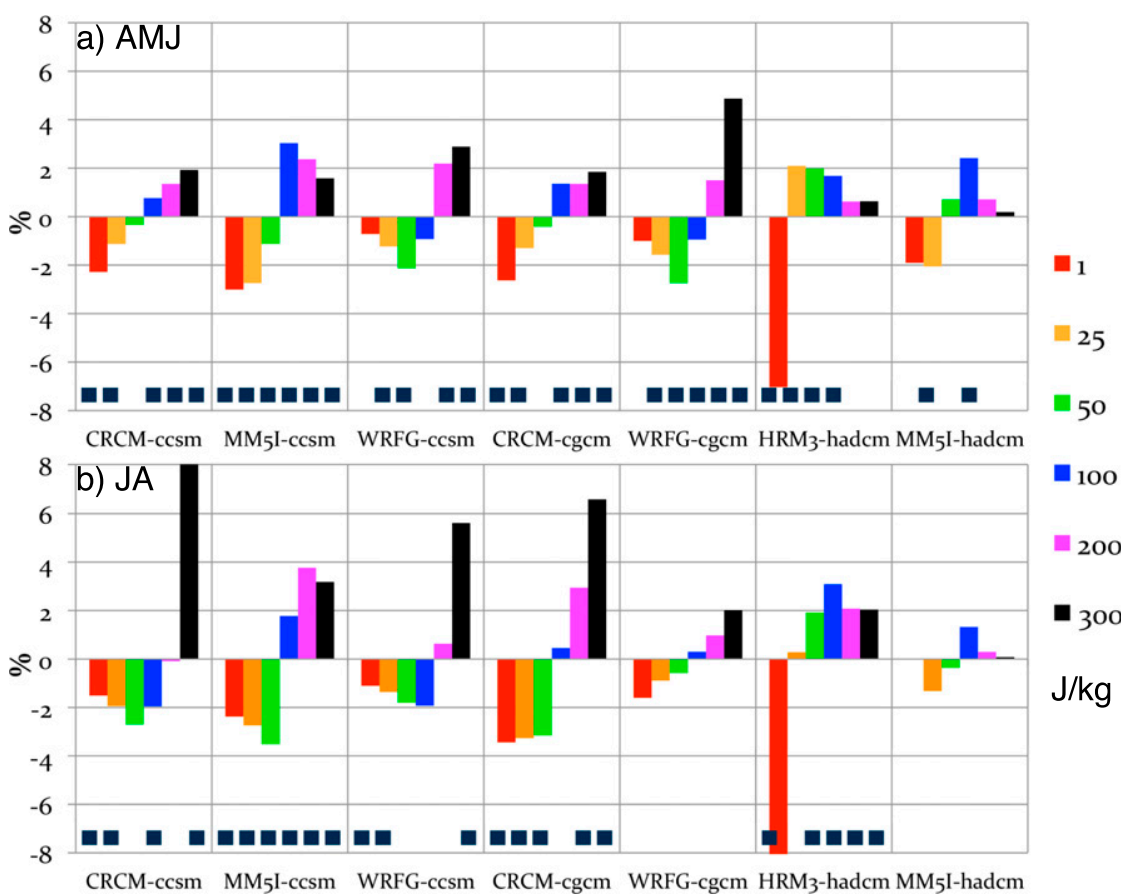

FIG. 8. Absolute change from the baseline period in the percent frequency of 0000 UTC CIN for (a) AMJ and (b) JA. The value associated with a bin is the starting point for values within that bin: for example, the red $1 \mathrm{~J} \mathrm{~kg}^{-1}$ bin shows the absolute change in the frequency of events with a magnitude greater than or equal to $1 \mathrm{~J} \mathrm{~kg}^{-1}$ and less than $25 \mathrm{~J} \mathrm{~kg}^{-1}$. Black squares across the bottom of (a),(b) indicate that the change in the corresponding bin is statistically significant at the 0.1 level. CIN is only considered if the value of CAPE at the time is greater than $100 \mathrm{~J} \mathrm{~kg}^{-1}$.

time of year, owing to the magnitude of the error and the importance of this feature in the indication of the poleward shift we are seeing in the other simulations. We will continue to include them here for completeness, however.

It is worth noting that the monsoon anticyclone and the tropical easterlies are fairly well simulated in these simulations despite the very poorly simulated midlatitude jet (Bukovsky et al. 2015). Because of this, and because the large scale is reasonably simulated for this region prior to May (note that the jet magnitude and position in April is considerably better than during the rest of the warm season in Fig. 10), the annual cycle of precipitation shown in Fig. 7 and the spatial distribution of precipitation in Figs. 5 and 6 for the HADCM-driven simulations are better than one might expect. However, upon careful examination of the time series of precipitation in Fig. 7, one can see that the decrease in precipitation in the HADCM-driven simulations starts earlier than it should and tapers off less rapidly than in the other simulations, consistent with the large-scale circulation problems that clearly start in May, as indicated by the midlatitude upper-level jet in Fig. 10, and consistent with the onset of the monsoon high later in the season, which is better simulated. Although the precipitation from the baseline HADCM-driven simulations is adequately represented we argue the projections from these simulations are not credible because of the poorly simulated evolution of the large-scale flow during the baseline and its failure to respond in a manner that is both physically plausible and consistent with warming in the future.

\section{3) GREAT Plains LOW-LEVEL JET}

In these simulations, local specific humidity and northward moisture transport are also projected to increase, which would help sustain a northward precipitation shift forced by the increased intensity of the monsoon anticyclone and northward shift in the midlatitude jet. This would also support the increase in precipitation in April in many of the RCMs. The projected increase in moisture transport is illustrated through the projected increase in the strength of the southerly mean flow associated with the Great Plains low-level jet and the increase in specific humidity seen in Figs. 11 and 9 (for AMJ) and Figs. S.2 and S.1 in the supplemental material (for JA). The increase in the strength of the GPLLJ core could also be contributing to the projected drying later in summer as more moisture 
a) CRCM-ccsm

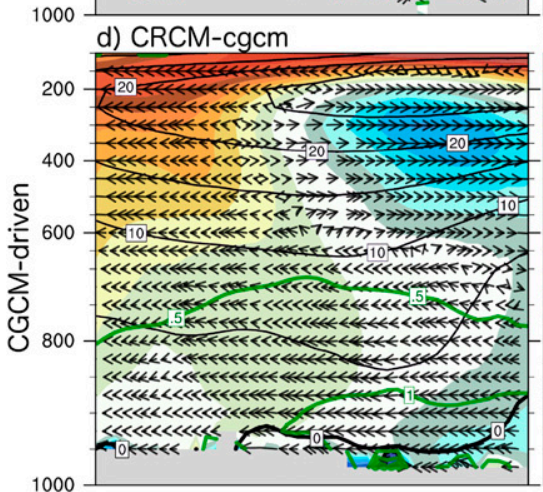

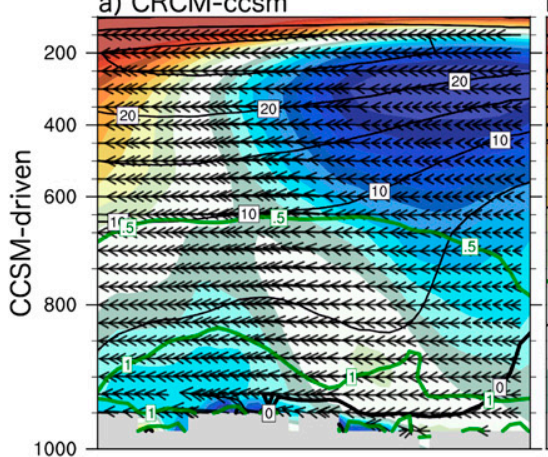

b) MM5I-ccsm

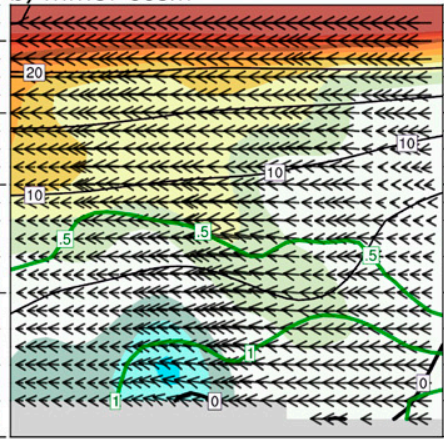

e) RCM3-cgcm

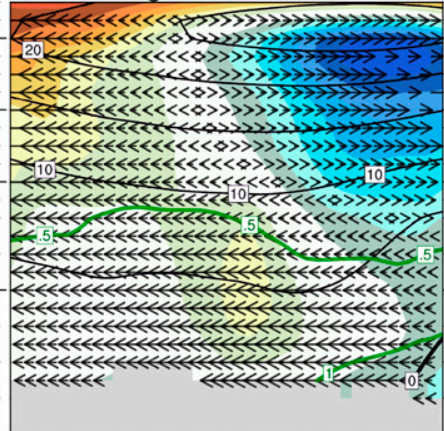

h) RCM3-gfdl

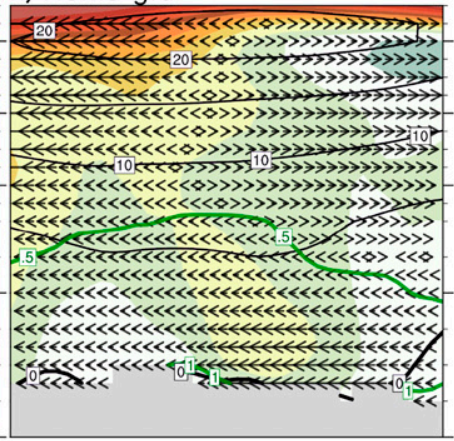

j) MM5I-hadcm

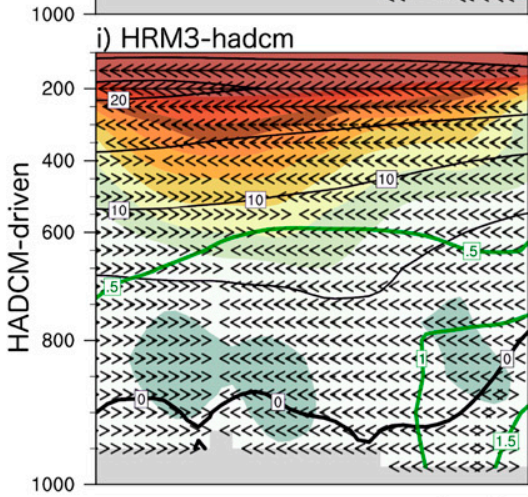

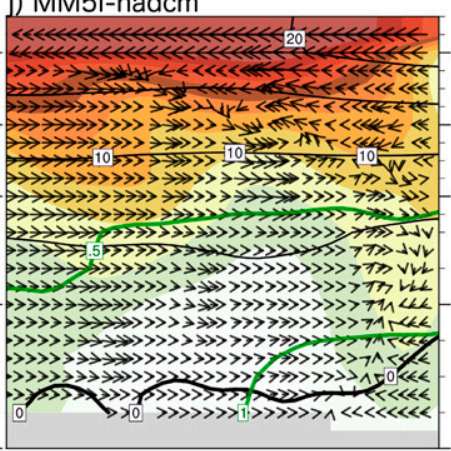

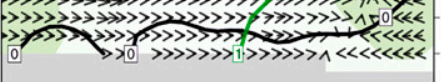

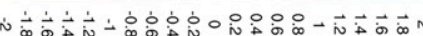

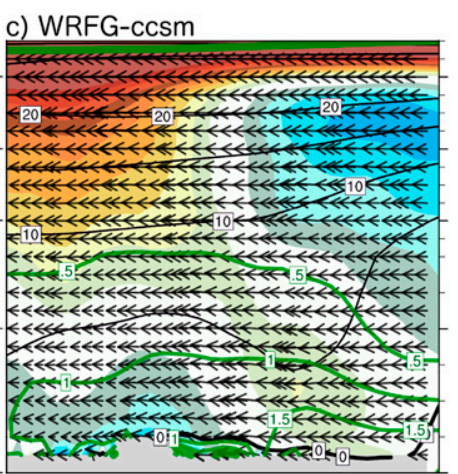

\section{f) WRFG-cgcm}

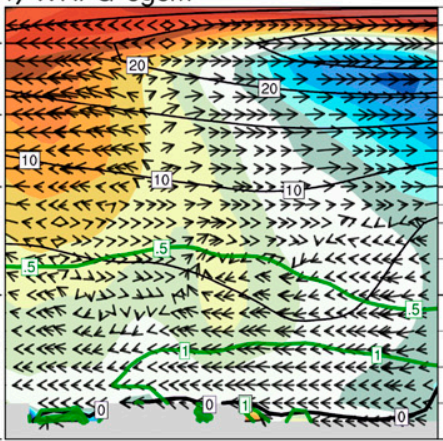

खाय<

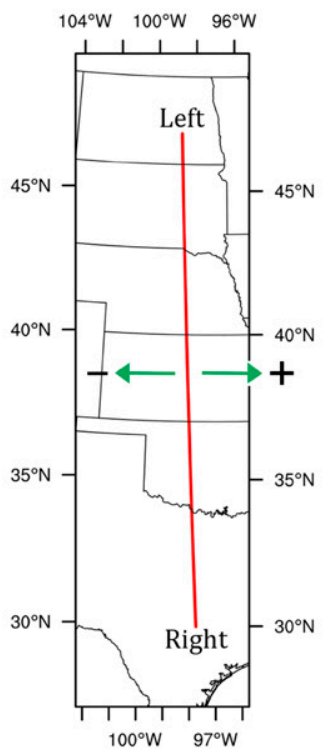

$(\mathrm{m} \mathrm{s}-1)$

FIG. 9. North-south-oriented vertical cross sections (top)-(bottom) organized by GCM driver through the Great Plains [(bottom right) location and orientation of the cross section (red line) are shown] of AMJ average change from the baseline to the future climate in specific humidity (green contours, contour interval $0.5 \mathrm{~g} \mathrm{~kg}^{-1}$ ), flow perpendicular to the cross section ( $\mathrm{m} \mathrm{s}^{-1}$, color fill; positive values are eastward change), and flow parallel to the cross section (thick black vectors). Also shown is the AMJ baseline average flow perpendicular to the cross section (black contours, contour interval $5 \mathrm{~m} \mathrm{~s}^{-1}$; positive values are eastward). Vertical axis is in pressure (hPa), and values below ground are masked in gray. Note that vertical motion has been multiplied by a factor of $10^{3} \mathrm{~m} \mathrm{~s}^{-1}$ for visibility and that the vertical wind component is not available and not shown for the HRM3-hadem or both RCM3 simulations. 

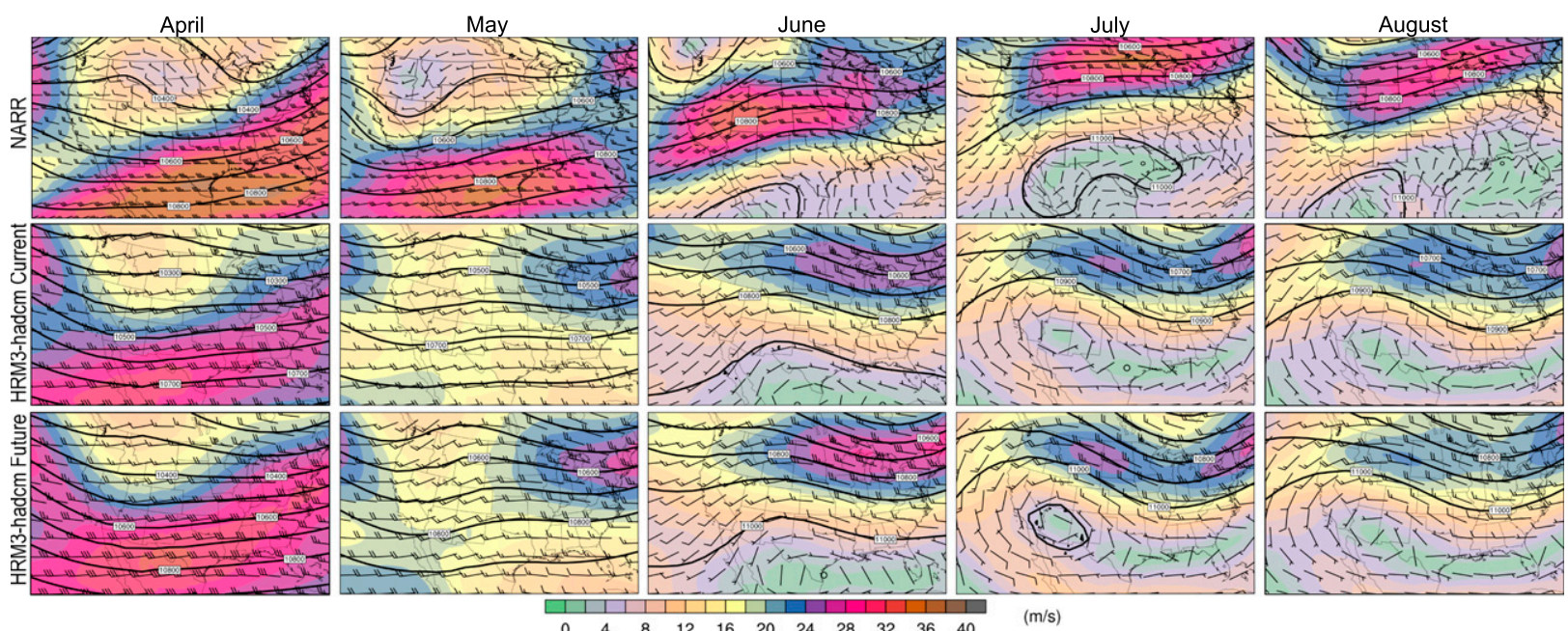

FIG. 10. Monthly average 250-hPa geopotential height (contour interval $100 \mathrm{~m}$; thick black lines), wind barbs ( $\mathrm{m} \mathrm{s}^{-1}$; full barbs are $10 \mathrm{~m} \mathrm{~s}^{-1}$, and half barbs are $5 \mathrm{~m} \mathrm{~s}^{-1}$ ), and winds speed ( $\mathrm{m} \mathrm{s}^{-1}$; color fill) from (top) the NARR for 1980-2004 (an overlapping period with the NARCCAP reanalysis-driven simulations) and the HRM3-hadcm (middle) baseline and (bottom) future simulations.

may be transported out of the region. The increase in the strength of the GPLLJ is varied, but present in all simulations except the HADCM-driven simulations in which the previously mentioned large-scale dynamical errors may be playing a role in it being an outlier here as well. The simulations also imply a westward expansion of the GPLLJ, although with little shift in the jet core, as the largest increases are generally centered to the west of the jet core in most of the simulations.

The projected changes in the GPLLJ may be due to the strengthening and westward expansion of the North Atlantic subtropical high (NASH; aka the Bermuda high), which is linked to greater warming over the United States versus the subtropical Atlantic Ocean and has been noted in both observations and other climate model studies [e.g., Cook et al. (2008), Weaver et al. (2009), Li et al. (2011), and Barandiaran et al. (2013), although there is some debate over the behavior of the NASH in observations (Diem 2013)]. The increase in the strength of the GPLLJ may also be due to enhanced temperature increases over the southern high plains versus the southeastern plains, as seen in observations (Feng et al. 2016). Therefore, we consider the broad response from the NARCCAP RCMs for this increase in the strength of the GPLLJ to be credible as well.

\section{4) LAND SURFACE FEEDBACKS}

The future changes in the larger-scale drivers of precipitation described above result in an earlier end to the spring wet period in the SGP. Averaged over the SGP, precipitation minus evaporation $(P-E)$ serves as a gross estimation of moisture convergence. Figure 12 shows the monthly mean relationship between $P-E$ and precipitation in the baseline and future experiments and how those relationships change in the future. During the rainy season (April, May, and early June), precipitation is driven primarily by larger-scale moisture transport, precipitation exceeds evaporation during these months, and soil moisture increases. In June, larger-scale sources of moisture decrease along with precipitation and evaporation begins to exceed precipitation in most of the models. When this happens, local evaporation starts to become an important source of moisture for the region, and land-atmosphere coupling begins (see Fig. S.3 in the supplemental material for ensemble mean coupling strength in the baseline period). By July and August, evaporation exceeds precipitation in all of the models, surface moisture strongly controls evapotranspiration, and land-atmosphere coupling is strong (Fig. S.3).

In the future, there is a clear change in the relationship between $P-E$ and precipitation in June, compared to other months (Fig. 12). While a few simulations have slight increases in moisture convergence (corresponding with an increase in rainfall, particularly in the HADCMdriven simulations and CCSM), most have decreases. This decrease results in the land surface drying out earlier in the summer, which in turn causes strong landatmosphere coupling to be established earlier in the summer.

Figure 12, right, shows the monthly changes in the TCI versus precipitation for April-August. In April and May, there is very little correlation between changes in precipitation and TCI, and it is likely not contributing to those changes. In June, however, changes in precipitation and TCI are well correlated. In July and 


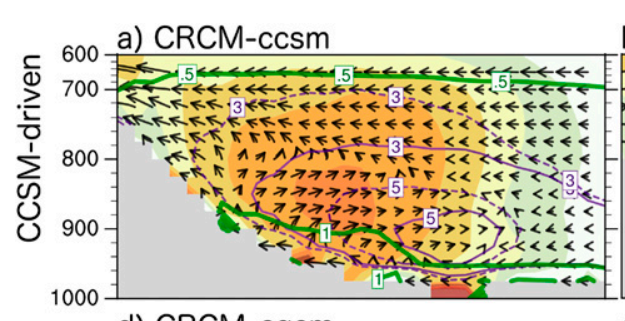

b) $\mathrm{MM} 5 \mathrm{I}-\mathrm{ccsm}$

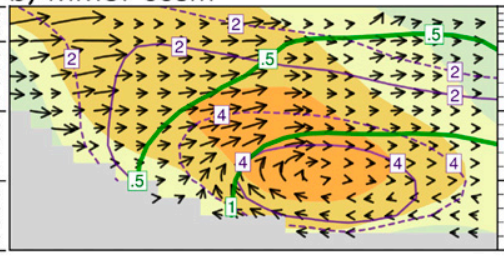

e) RCM3-cgcm

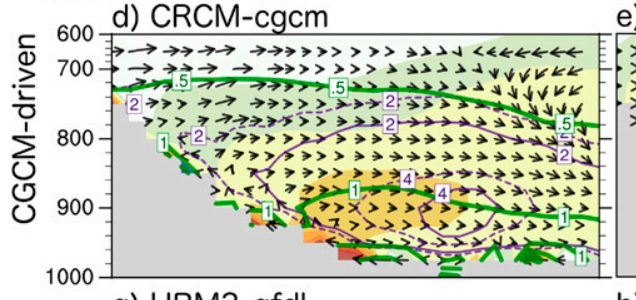

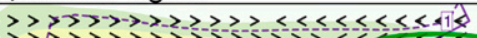

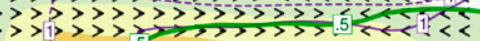

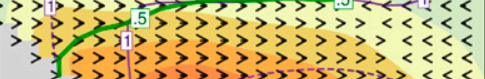

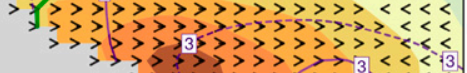
c) WRFG-ccsm

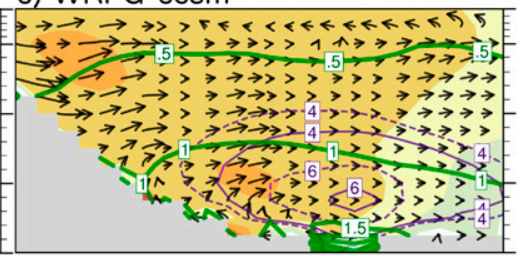

f) WRFG-cgcm

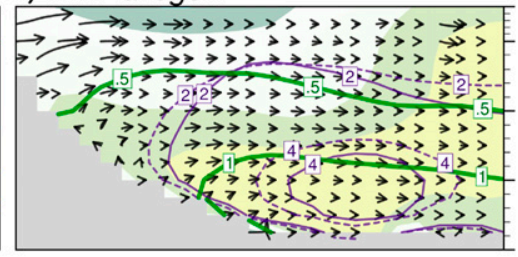

h) RCM3-gfdl
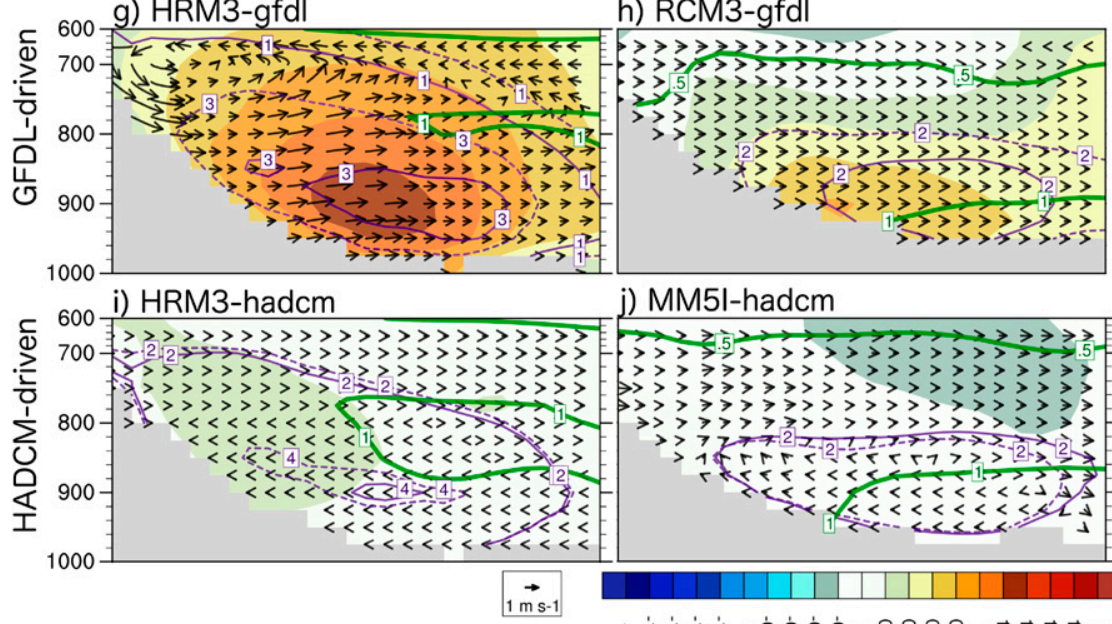

j) MM5I-hadcm

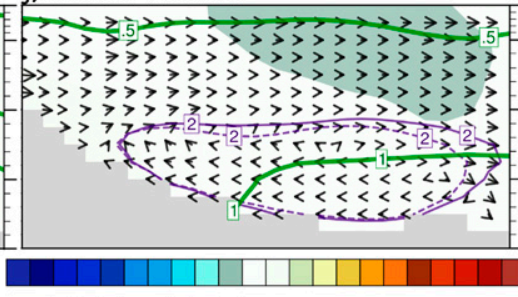

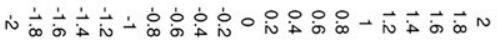

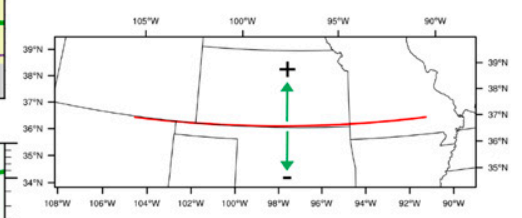

FIG. 11. Vertical cross sections (top)-(bottom) organized by GCM driver across the SGP [(bottom right) location and orientation of the cross section (red line)] of AMJ average change from the baseline to the future climate in specific humidity (green contours, contour interval $\left.0.5 \mathrm{~g} \mathrm{~kg}^{-1}\right)$, flow perpendicular to the cross section $\left(\mathrm{m} \mathrm{s}^{-1}\right.$, color fill; positive values are northward), and flow parallel to the cross section (thick black vectors). Also shown is the AMJ average flow perpendicular to the cross section for the baseline and future ( $\mathrm{m} \mathrm{s}^{-1}$, purple contours, with future contours dashed; positive is northward; two contours for each period are shown only, one contour for the greatest integer value in the baseline period and one $2 \mathrm{~m} \mathrm{~s}^{-1}$ lower). Vertical axis is in pressure (hPa), and values below ground are masked in gray. Note that vertical motion has been multiplied by a factor of $10^{3} \mathrm{~m} \mathrm{~s}^{-1}$ for visibility and that the vertical wind component is not available and not shown for the HRM3-hadem or both RCM3 simulations.

August, while a few models have increases in TCI that correspond with decreases in precipitation, across all of the models there is little correlation between changes in precipitation and TCI.

The simulations with increases in TCI in June suggest that strong land-atmosphere coupling will be established earlier in the summer by midcentury and that June coupling is transitioning to be more like the stronger coupling seen in July and August. This result supports the findings of Dirmeyer et al. (2013). An increase in landatmosphere coupling in June means that local evaporation will serve as an important source of moisture for the SGP earlier in the season. As the land surface dries out earlier in the season, there is less moisture available for precipitation recycling later in the season.
In CCSM in July and August, there is an increase in both precipitation and terrestrial coupling (TC) that is worth noting, as the increase in TC may be exacerbating the increase in precipitation that is likely just an artifact of the convective parameterization and a response to moisture and CAPE increases. Other forcing mechanisms in this GCM would otherwise suggest that precipitation should be decreasing in summer, as it is in the RCMs forced by CCSM. Land-atmosphere coupling is known to be strong in this version of CCSM. The land surface model used, the Community Land Model, version 3 (CLM3; Oleson et al. 2004), is known to have a dry soil moisture bias that leads to unrealistic surface flux responses (Oleson et al. 2008). Also, precipitation in the atmospheric component of CCSM, the Community 
Baseline (P-E vs. P)
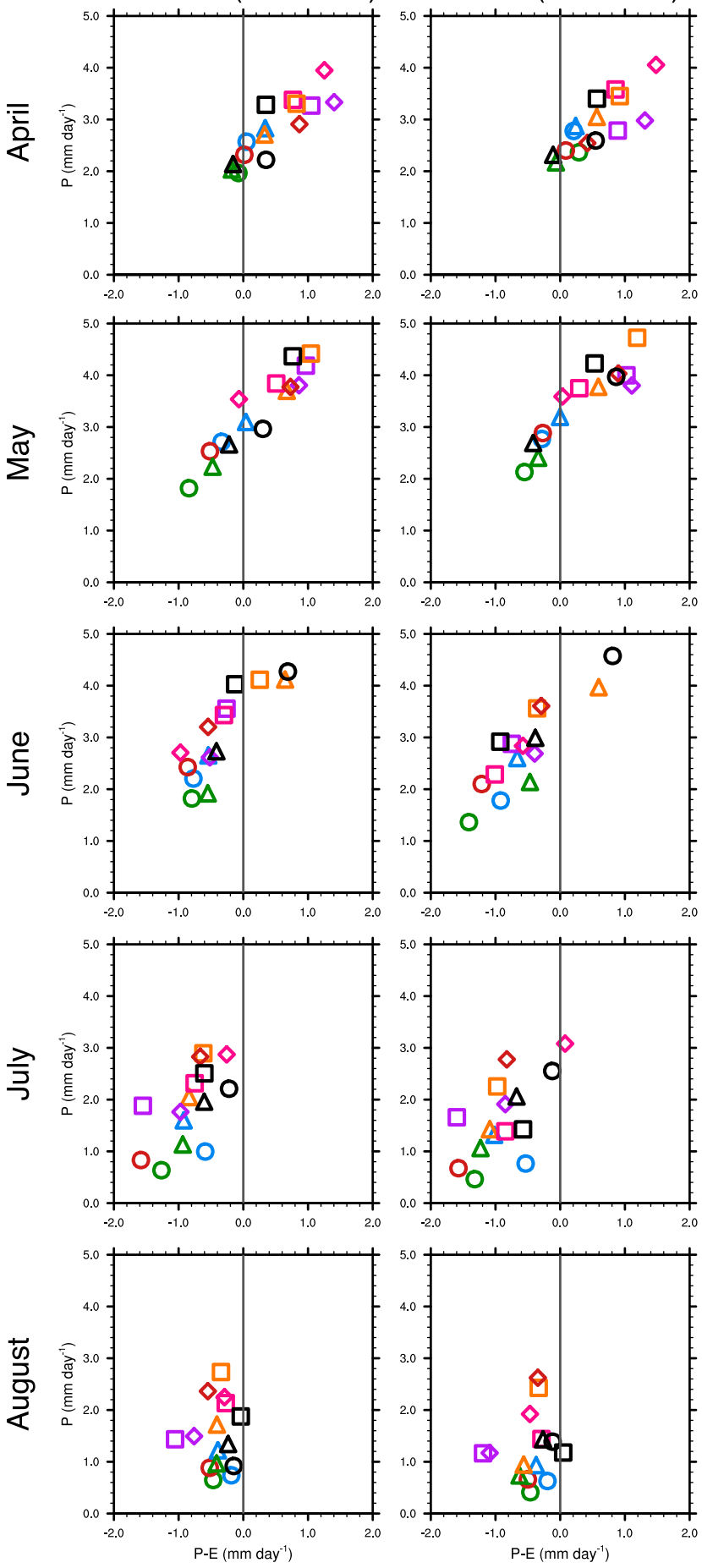

O CCSM $\triangle$ CGCM3

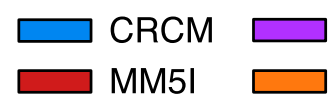

Change (P-E vs. P)
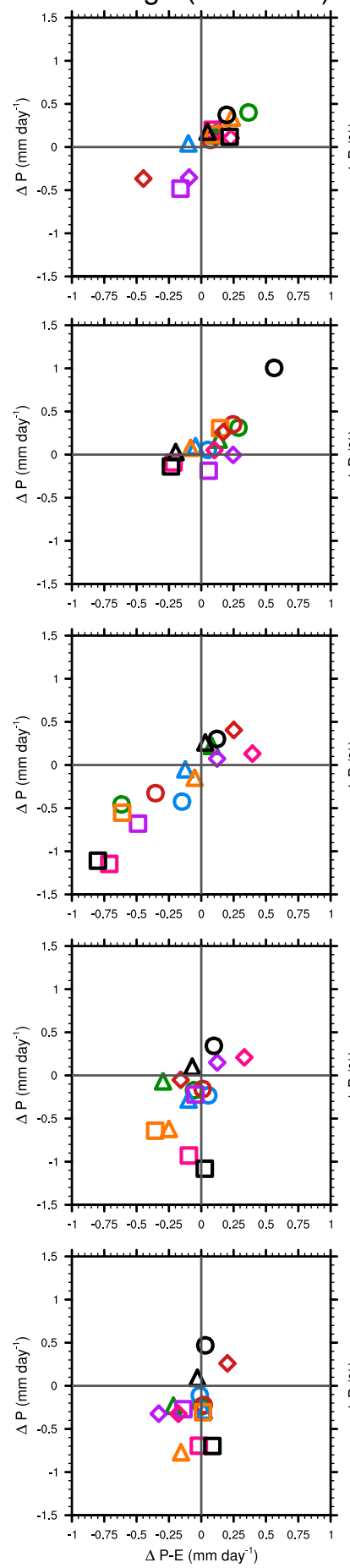

$\square$ GFDL $\diamond$ HadCM3
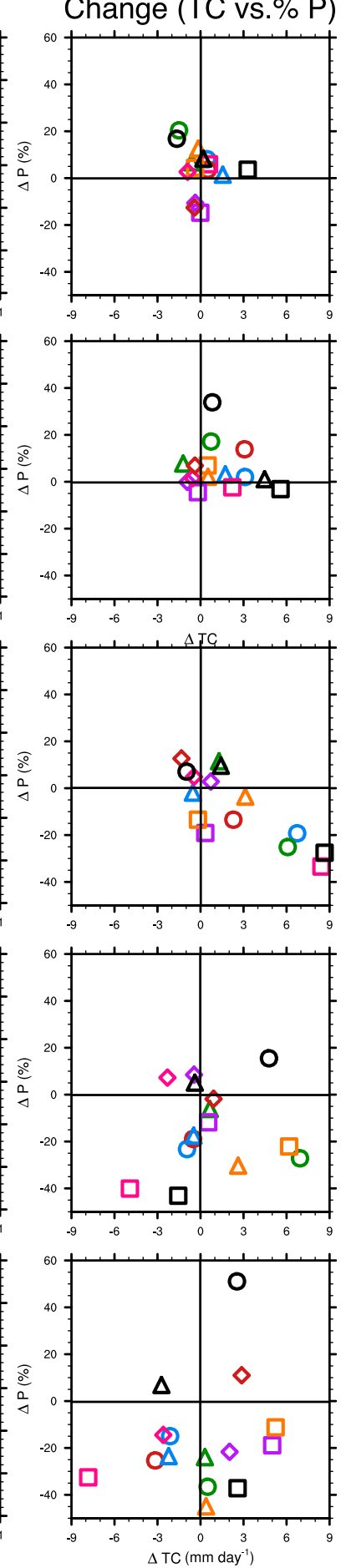

ECP2 $\square$ HRM3

$\mathrm{RCM} 3$

WRFG

FIG. 12. Monthly average $P-E$ vs $P$ from the (left) baseline and (center left) future periods as well as (center right) the absolute change from baseline to future in $P-E$ vs $P$ and (right) the change in the TCI vs the percent change in $P$ over the SGP region outlined in Fig. 1. 
Atmosphere Model, version 3 (CAM3), is known to be highly sensitive to evapotranspiration fluxes (Guo et al. 2006; McCrary and Randall 2010).

It is likely that the change in terrestrial coupling strength is further enhancing the drying where it is projected in June. Because the coupling strength is high in this region, some enhancement of the precipitation response is expected, even without a change in the coupling strength itself. With the existing strong coupling, less precipitation would lead to less soil moisture, less evaporation, and then less precipitation. Strong correlations between changes in precipitation and soil moisture and sensible heat flux are indeed evident in JA in the models (Fig. S.4 in the supplemental material). The strong coupling may also be enhancing the decrease in precipitation driven by larger-scale atmospheric changes through modulation of CIN, as CIN would also increase (as illustrated in Fig. 8) as soil moisture decreased (Myoung and Nielsen-Gammon 2010).

\section{Projections of additional precipitation characteristics}

Changes in the processes discussed in section $4 \mathrm{~b}$ are also driving changes in other characteristics of warmseason precipitation in the SGP along with the changes in the mean as discussed in section 3. In AMJ, the number of days with no precipitation is increasing (Table 3) because of the increased strength of the monsoon anticyclone, the increase in the frequency of high CIN (Fig. 8), and the earlier end to the SGP wet period as a result of the increasing strength of the monsoon anticyclone. When it does rain, it is more intense because of the greater availability of moisture (Table 3). There is a concurrent shift in the frequency distribution of precipitation as well, with a decrease in the frequency of precipitation events of nearly all magnitudes, except the most intense (Fig. 13a). In the SGP, this all implies more intense but less frequent convection. Convective environment parameters for severe events are projected to change in such a way that there is a greater likelihood that when convection occurs, it will happen in an environment that is more conducive to severe thunderstorms than in the past. Figure 14a illustrates this projected increase through an increase in the number of days in which the environment is conducive for severe and significant severe thunderstorms in seven of the RCMs (calculations of those complex indices were restricted by data availability). These changes are predominantly due to an increase in the number of high CAPE days, including days on which the triggering of convection is not
TABLE 3. Percent change from the baseline to the future in the intensity of precipitation and the number of dry days. Intensity is defined as the average intensity of precipitation on days with precipitation above a trace, and dry days are days when there is no precipitation above a trace. A trace is defined as $0.25 \mathrm{~mm}_{\text {day }}{ }^{-1}$.

\begin{tabular}{lccccc}
\hline \hline & \multicolumn{3}{c}{ AMJ } & & \multicolumn{2}{c}{ JA } \\
\cline { 2 - 3 } \cline { 5 - 6 } RCM-GCM & Intensity & Dry days & & Intensity & Dry days \\
\hline CRCM-ccm & 2.65 & 2.11 & & -4.82 & 5.56 \\
MM5I-ccsm & 7.47 & 4.20 & & -6.95 & 6.74 \\
WRFG-ccsm & 8.04 & 0.54 & & -11.44 & 5.01 \\
CRCM-cgcm & 6.72 & 3.95 & & -5.14 & 6.11 \\
RCM3-cgcm & 4.76 & 1.52 & & -2.32 & 8.84 \\
WRFG-cgcm & 9.75 & 1.14 & & -3.89 & 2.27 \\
ECP2-gfdl & 0.34 & 5.92 & & -0.88 & 4.15 \\
HRM3-gfdl & -1.33 & 4.99 & & -27.74 & 4.99 \\
RCM3-gfdl & 4.42 & 3.07 & & 4.93 & 7.52 \\
ECP2-hadcm & 8.26 & 4.54 & & 9.57 & 6.37 \\
HRM3-hadcm & 8.36 & 2.62 & & 4.78 & 3.56 \\
MM5I-hadcm & 7.31 & 1.76 & 6.38 & 0.91 \\
RCM mean & 5.56 & 3.03 & & -3.13 & 5.17 \\
\hline
\end{tabular}

severely inhibited $\left(\mathrm{CIN}<100 \mathrm{~J} \mathrm{~kg}^{-1}\right)$, and less because of changes in shear, as these changes are more mixed, but mostly positive. The changes in these parameters are also statistically significant over much of the SGP region, with coverage values ranging from $32 \%$ to $96 \%$ of the grid points depending on the model and parameter (with the lowest values coming from the HADCM-driven simulations), with an average of $69 \%$ coverage (spatial maps of change not shown). These changes are physically plausible with increases in surface temperature and specific humidity as both would act to increase CAPE.

In JA, there is an expected increase in dry days, with the broadening of the monsoon high. Most of the RCMs project a decrease in the intensity of precipitation when it does rain and a strong decrease in the frequency of precipitation events of almost all magnitudes as well (Table 3; Fig. 13b). There is also an increase in the number of days conducive to severe and significant severe thunderstorms in JA, in several of the RCMs, but less so than in AMJ, and mostly because of an increase in high CAPE days in several of the simulations (Fig. 14b). However, the increase is less likely in some of the RCMs in an environment with CIN less than $100 \mathrm{~J} \mathrm{~kg}^{-1}$. Similarly, these environments would be increasingly unlikely to be realized in JA given the other increasingly unfavorable conditions for convection to occur in JA, as also indicated through the increase in the number of dry days, decreases in the frequency of convection, and increases in frequency of high CIN. Furthermore, these changes are generally statistically significant over less of the domain, with coverage ranging from 


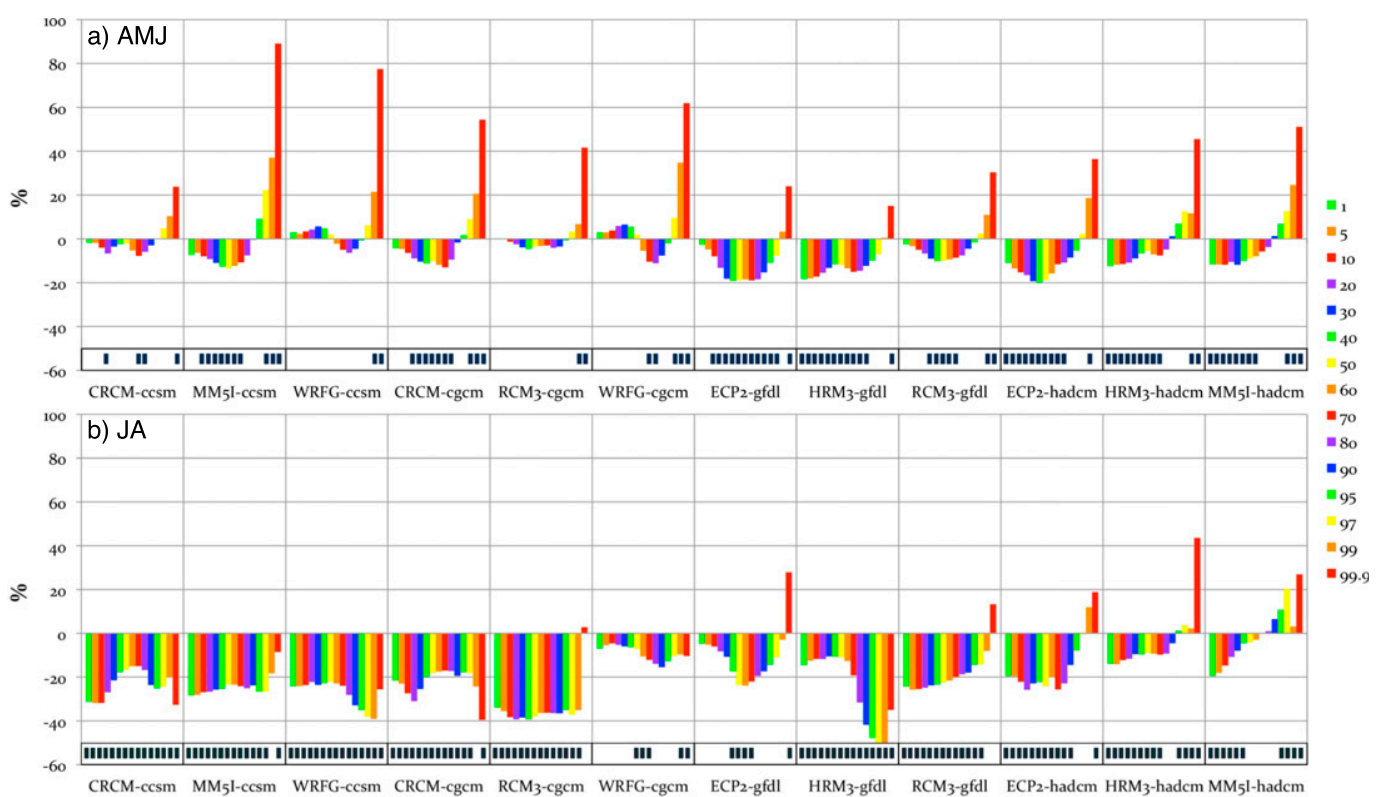

FIG. 13. Percent change in the percent frequency of 3-hourly precipitation rates for (a) AMJ and (b) JA. Rates are binned by their percentile in the baseline climate. The value associated with a bin is the starting point for values within that bin; for example, the green 95th-percentile bin shows the percent change in the frequency of events with a magnitude greater than or equal to the 95th-percentile magnitude and less than the 97th-percentile magnitude in the current climate. Dark squares across the bottom of (a),(b) indicate that the change in the corresponding bin is statistically significant at the 0.1 level.

$34 \%$ to $87 \%$ of the grid points depending on the simulation and parameter with an average of $60 \%$ coverage.

\section{Summary and discussion}

Midcentury projections from the NARCCAP RCMs for the SGP indicate an increase in mean precipitation in early spring in the SGP but an earlier shift in precipitation poleward into the central Great Plains and Midwest through late spring and early summer, followed by an intensification of the dry season in July and August. These projections are consistent although weaker in ensembles of CMIP3 and CMIP5 simulations. While the details on the timing of these changes in mean precipitation and the magnitude of the changes vary across the individual RCMs, we find the consistent part of this response to anthropogenic warming to be credible in all NARCCAP simulations except the HADCM-driven simulations. That is because this mean change is forced by consistently simulated, physically plausible changes in the monsoon high, upper-level jet, the GPLLJ, and amplified by land-atmosphere coupling.

The schematic provided in Fig. 15 summarizes the consistent part of the changes in these complex, intertwined processes. As illustrated, the monsoon high strengthens and expands in the future and suppresses convection over a broader region, essentially driving it farther north to a more conducive environment, the upper-level jet shifts northward earlier in the warm season as well, and the GPLLJ is stronger in the future supplying more moisture for earlier season precipitation and a greater flux of moisture northward later in the season. These larger-scale dynamical changes force land-atmosphere coupling to initiate earlier in the warm season, so the SGP dries out earlier and extreme drying occurs later in the summer as a result.

In AMJ, the credible RCMs also project an increase in the intensity of precipitation, an increase in the frequency of very heavy precipitation events, with a decrease in the frequency of lighter events, and an increase in the number of days with environments conducive to severe thunderstorms, although there is also an increase in the frequency of very strong capping inversions. In $\mathrm{JA}$, the credible RCMs also project a decrease in the intensity of precipitation, a larger increase in the number of dry days, a decrease in the frequency of precipitation events of nearly every magnitude, and an increase in the number of days with environments conducive to severe thunderstorms, although it does not seem likely that these would be often realized as the environment is projected to become less favorable for the triggering of convection in JA. 


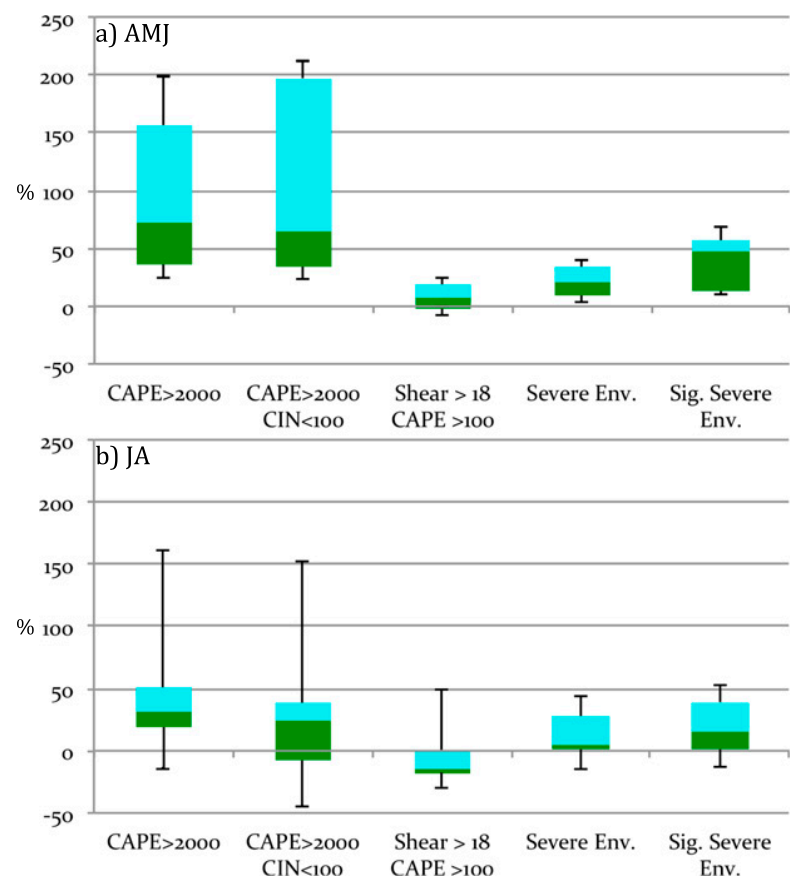

FIG. 14. Percent change from the baseline to the future in the number of days per season that meet the criteria for the given category at 0000 UTC averaged across the SGP region outlined in Fig. 1 for (a) AMJ and (b) JA. The median value of the seven models for which these criteria can be calculated is the dividing line between the turquoise and green. The top of the box represents the 75 th percentile of the model projections and the bottom the 25 th percentile. The top whisker represents the maximum from the seven projections and the bottom the minimum.

Out of the 12 NARCCAP RCM simulations, we find that the projections from 3 of them are clearly not credible, the HADCM-driven simulations. The error in the simulation of the upper-level midlatitude jet stream in these simulations during the warm season clearly affects the response to anthropogenic warming in these simulations. We find the projections from the others to be credible, in general. This is not to say that the other 9 simulations are not biased and that those biases are not affecting the projections in some way (e.g., magnitude or timing of response during the season) but that they are not influencing the ability of the RCMs to respond to the consistent and credible parts of the larger-scale changes in the mechanisms driving the mean precipitation changes. If we remove the HADCM-driven changes from the NARCCAP ensemble mean, we see stronger signals for mean precipitation change through the season, as these projections are not consistent with the others (cf. Figs. 16 and 2a).

Overall, we also find the baseline simulation of and projections of mean precipitation to be more credible from the RCMs than their driving GCMs. Specifically, three-quarters of the RCM simulations are credible and show consensus on mean precipitation changes from April through August; only half of their GCM drivers are without fatal errors or very questionable projections. The HADCM response is not credible for the reasons mentioned above, and CCSM has precipitation changes that are not physically plausible given the changes in the larger-scale drivers of the precipitation. The precipitation in the RCMs forced by CCSM large-scale fields responds to the larger-scale changes in a way that is much more plausible, suggesting great added value in these simulations. The mean precipitation changes in CGCM and CCSM in summer (an increase and a strong increase, respectively) may be due to their convective scheme not realistically taking into account convective inhibition and responding chiefly to the increase in moisture and instability and exacerbated by strong terrestrial coupling (which increases in the CCSM).

Generally, the projections for mean precipitation from the RCMs agree with the projections from the CMIP suites of simulations, but the changes are greater in magnitude in the RCM ensemble. There are several possible reasons for this. In JA, the drying signal in the RCM ensemble may be greater because half of the RCMs (driven by CCSM and CGCM) have strong dry biases during JA to begin with, which could, through the strong surface coupling, lead to enhanced drying. During the full season, it is also possible that the difference between the RCM and GCM ensemble mean changes is due to differences in how well the precipitation pattern is simulated to begin with (it is better in the RCMs than their drivers, as discussed in section 4a), and a poor baseline simulation of precipitation could cause the influence of the largerscale changes on precipitation to manifest in a less distinct way. The manner in which convection is parameterized may also play a role in multiple GCMs, as it likely is in the CGCM and CCSM runs used in NARCCAP (e.g., whether the influence of CIN in inhibiting convection is parameterized well). Additionally, the strength of the precipitation change in the RCMs versus the GCMs could be heavily influenced by whether enough of the GCMs in the ensembles have the same synoptic and large-scale changes as seen here in most of the simulations or if they have biases in their larger-scale features affecting the projections as in the HADCM and HADCM-driven simulations. Clearly many of them show similar signals for changes in the GPLLJ and the expansion of the Hadley cell, which should force the upper-level jet northward, if it exists in the simulation (see the references used previously in the corresponding sections), whether or not the precipitation is responding in an appropriate manner. Individually assessing all of the GCMs included in Fig. 2 is outside the scope of this study, although it would be a warranted topic for future work. Further work 


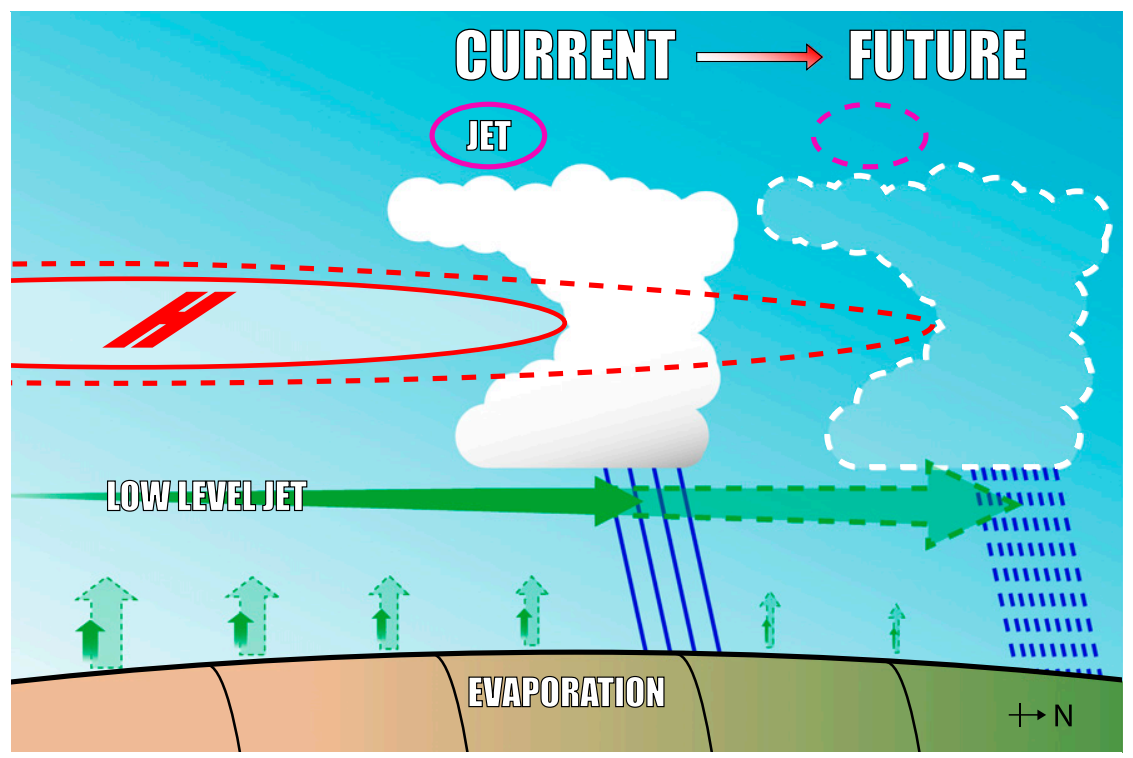

FIG. 15. Schematic diagram summarizing the changes projected for the SGP by midcentury by the NARCCAP RCMs.

could also include a similar analysis for this region with an ensemble of well-performing, convection-permitting simulations (regional and global), as the RCMs used here do still rely on convective parameterizations, just like the GCMs. This would verify that the changes in the largerscale drivers of precipitation are having the same effect on convection in the future when the convection is simulated even more realistically.

In this analysis of the NARCCAP simulations we find consensus and credibility across the majority of the simulations for their change in mean precipitation. Consensus and credibility together are not a given. The results of this study are in great contrast to analyses of the NARCCAP simulations for warm-season precipitation in the North American monsoon region by Bukovsky et al. $(2013,2015)$ and in the northeastern United States by
Thibeault and Seth (2014). In Bukovsky et al. (2013, 2015), there was great consensus, but little credibility. The less credible a simulation, in that case, the greater the decrease was in projected mean precipitation. In Thibeault and Seth (2014), results were generally mixed with little consensus, even in the more credible simulations. In contrast, here we have robust larger-scale changes that are physically consistent with a warmer environment and the RCMs are responding in a plausible way to this forcing. Similar mean changes in precipitation manifest in the CMIP3 and CMIP5 ensembles also, as a result. Therefore, in this case, the NARCCAP model biases become less important to the overall story of mean precipitation change in the SGP. Because we have plausible physical arguments that support the model consensus, we have confidence in these results.

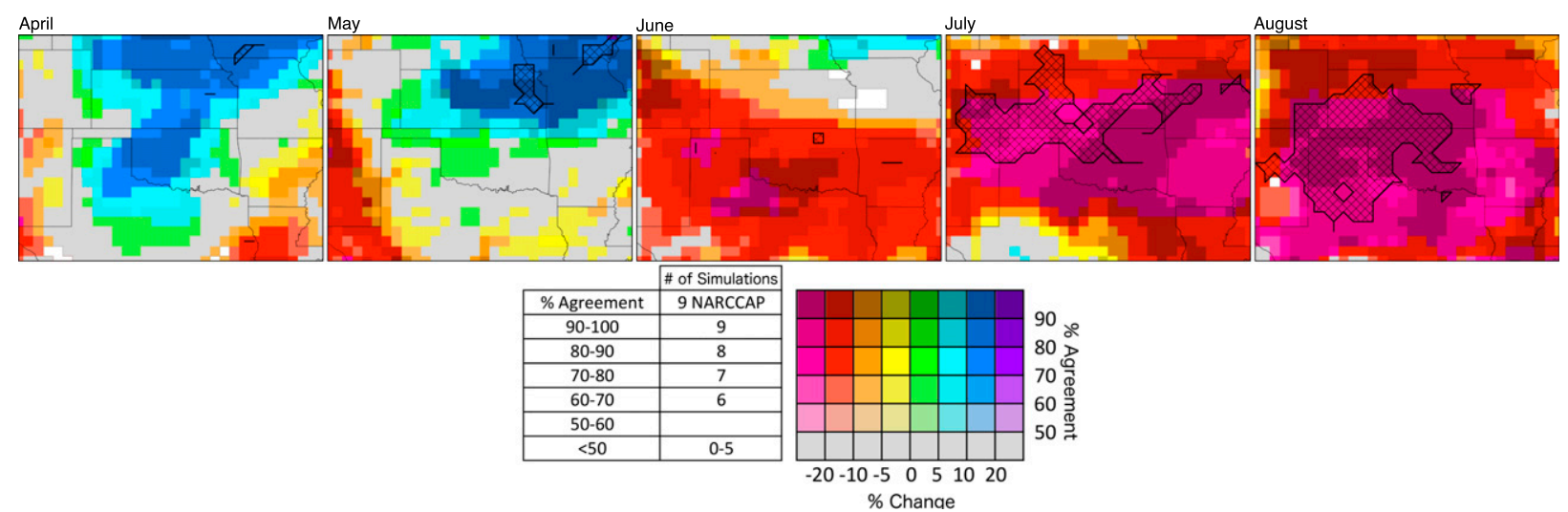

FIG. 16. As in Fig. 2, but for the NARCCAP ensemble excluding the three HADCM-driven simulations. 
Acknowledgments. We wish to thank Jeremy Cain for his work creating the schematic summary figure for this paper. We also want to thank the three reviewers and the editor for their comments on the manuscript. We acknowledge NARCCAP for providing the data used in this paper. NARCCAP was funded by the National Science Foundation (NSF), the U.S. Department of Energy (DOE), the National Oceanic and Atmospheric Administration (NOAA), and the U.S. Environmental Protection Agency Office of Research and Development. We also acknowledge the World Climate Research Programme's Working Group on Coupled Modelling, which is responsible for CMIP, and we thank the various climate modeling groups for producing and making available their model output. For CMIP the DOE Program for Climate Model Diagnosis and Intercomparison provides coordinating support and led development of software infrastructure in partnership with the Global Organization for Earth System Science Portals. CPC U.S. unified precipitation data were provided by the NOAA/OAR/ESRL PSD, Boulder, Colorado, from their website (at http://www.esrl.noaa. gov/psd/data/gridded/data.unified.daily.conus.html), and NARR data were obtained from the NCEP website (at http://www.emc.ncep.noaa.gov/mmb/rreanl/). We would also like to acknowledge high-performance computing support from Yellowstone (http://n2t.net/ ark:/85065/d7wd3xhc) for the use of the Geyser analysis cluster provided by NCAR's Computational and Information Systems Laboratory (CISL 2012), sponsored by the NSF. The authors also acknowledge the support of the NOAA Climate Program Office Modeling, Analysis, Predictions and Projections (MAPP) Program. Work was supported under Grants NA11AOR4310111 (NCAR) and NA11OAR4310109 (UConn). At NCAR, this work was also supported by the NCAR Weather and Climate Impacts Assessment Science Program, funded by NSF under NCAR Cooperative Agreement Contract M0856145.

\section{REFERENCES}

Anderson, J. L., and Coauthors, 2004: The new GFDL global atmosphere and land model AM2-LM2: Evaluation with prescribed SST simulations. J. Climate, 17, 4641-4673, doi:10.1175/JCLI-3223.1.

Ashley, W. S., T. L. Mote, G. P. Dixon, S. L. Trotter, E. J. Powell, J. D. Durkee, and A. J. Grundstein, 2003: Distribution of mesoscale convective complex rainfall in the United States. Mon. Wea. Rev., 131, 3003-3017, doi:10.1175/1520-0493(2003)131<3003: DOMCCR $>2.0 . \mathrm{CO} ; 2$.

Barandiaran, D., S. Y. Wang, and K. Hilburn, 2013: Observed trends in the Great Plains low-level jet and associated precipitation changes in relation to recent droughts. Geophys. Res. Lett., 40, 6247-6251, doi:10.1002/2013GL058296.
Barsugli, J. J., and Coauthors, 2013: The practitioner's dilemma: How to assess the credibility of downscaled climate projections. Eos, Trans. Amer. Geophys. Union, 94, 424-425, doi:10.1002/2013EO460005.

Brekke, L. D., M. D. Detinger, E. P. Maurer, and M. Anderson, 2008: Significance of model credibility in estimating climate projection distributions for regional hydroclimatological risk assessments. Climatic Change, 89, 371-394, doi:10.1007/s10584-007-9388-3.

Brooks, H. E., J. W. Lee, and J. P. Craven, 2003: The spatial distribution of severe thunderstorm and tornado environments from global reanalysis data. Atmos. Res., 67-68, 73-94, doi:10.1016/S0169-8095(03)00045-0.

Brubaker, K. L., P. A. Dirmeyer, A. Sudradjat, B. S. Levy, and F. Bernal, 2001: A 36-yr climatological description of the evaporative sources of warm-season precipitation in the Mississippi River basin. J. Hydrometeor., 2, 537-557, doi:10.1175/ 1525-7541(2001)002<0537:AYCDOT>2.0.CO;2.

Bukovsky, M. S., and D. J. Karoly, 2011: A regional modeling study of climate change impacts on warm-season precipitation in the central United States. J. Climate, 24, 1985-2002, doi:10.1175/ 2010JCLI3447.1.

— D. J. Gochis, and L. O. Mearns, 2013: Towards assessing NARCCAP regional climate model credibility for the North American monsoon: Current climate simulations. J. Climate, 26, 8802-8826, doi:10.1175/JCLI-D-12-00538.1.

— C. M. Carrillo, D. J. Gochis, D. M. Hammerling, R. R. McCrary, and L. O. Mearns, 2015: Towards assessing NARCCAP regional climate model credibility for the North American monsoon: Future climate simulations. J. Climate, 28, 6707-6728, doi:10.1175/JCLI-D-14-00695.1.

Carbone, R. E., J. D. Tuttle, D. A. Ahijevych, and S. B. Trier, 2002: Inferences of predictability associated with warm season precipitation episodes. J. Atmos. Sci., 59, 2033-2056, doi:10.1175/1520-0469(2002)059<2033:IOPAWW>2.0.CO;2.

Caya, D., and R. Laprise, 1999: A semi-implicit semi-Lagrangian regional climate model: The Canadian RCM. Mon. Wea. Rev., 127, 341-362, doi:10.1175/1520-0493(1999)127<0341: ASISLR $>2.0 . \mathrm{CO} ; 2$.

Changnon, S. A., 2001: Thunderstorm rainfall in the conterminous United States. Bull. Amer. Meteor. Soc., 82, 1925-1940, doi:10.1175/1520-0477(2001)082<1925:TRITCU>2.3.CO;2.

Christensen, J. H., and Coauthors, 2013: Climate phenomena and their relevance for future regional climate change. Climate Change 2013: The Physical Science Basis, T. F. Stocker et al., Eds., Cambridge University Press, 1217-1308.

COESA, 1976: U.S. Standard Atmosphere, 1976. NOAA, 227 pp. Cohen, J., 1960: A coefficient of agreement for nominal scales. Educ. Psychol. Meas., 20, 37-46, doi:10.1177/001316446002000104.

Collins, W. D., and Coauthors, 2006: The Community Climate System Model: CCSM3. J. Climate, 19, 2122-2143, doi:10.1175/JCLI3761.1.

Computational and Information Systems Laboratory, 2012: Yellowstone: IBM iDataPlex system. National Center for Atmospheric Research. [Available online at https://www2.cisl. ucar.edu/supercomputer/yellowstone.]

Cook, K. H., E. K. Vizy, Z. S. Launer, and C. M. Patricola, 2008: Springtime intensification of the Great Plains low-level jet and Midwest precipitation in GCM simulations of the twenty-first century. J. Climate, 21, 6321-6340, doi:10.1175/2008JCLI2355.1.

Dai, A., 2006: Precipitation characteristics in eighteen coupled climate models. J. Climate, 19, 4605-4630, doi:10.1175/JCLI3884.1.

Delworth, T., and S. Manabe, 1988: The influence of potential evaporation on the variabilities of simulated soil wetness and climate. 
J. Climate, 1, 523-547, doi:10.1175/1520-0442(1988)001<0523 TIOPEO $>2.0 . \mathrm{CO} ; 2$.

Diem, J., 2013: Comments on "Changes to the North Atlantic subtropical high and its role in the intensification of summer rainfall variability in the southeastern United States." J. Climate, 26, 679-682, doi:10.1175/JCLI-D-11-00390.1.

Dirmeyer, P. A., 2011: The terrestrial segment of soil moistureclimate coupling. Geophys. Res. Lett., 38, L16702, doi:10.1029/ 2011 GL048268.

— , and K. L. Brubaker, 2007: Characterization of the global hydrologic cycle from a back-trajectory analysis of atmospheric water vapor. J. Hydrometeor., 8, 20-37, doi:10.1175/JHM557.1.

- , and Coauthors, 2012: Evidence for enhanced landatmosphere feedback in a warming climate. J. Hydrometeor., 13, 981-995, doi:10.1175/JHM-D-11-0104.1.

_ - Y. Jin, B. Singh, and X. Yan, 2013: Evolving land-atmosphere interactions over North America from CMIP5 simulations. J. Climate, 26, 7313-7327, doi:10.1175/JCLI-D-12-00454.1.

Doswell, C. A., and E. N. Rasmussen, 1994: The effect of neglecting the virtual temperature correction on CAPE calculations. Wea. Forecasting, 9, 625-629, doi:10.1175/ 1520-0434(1994)009<0625:TEONTV>2.0.CO;2.

$\longrightarrow$, H. E. Brooks, and M. P. Kay, 2005: Climatological estimates of daily local nontornadic severe thunderstorm probability for the United States. Wea. Forecasting, 20, 577-595, doi:10.1175/ WAF866.1.

Duffy, P. B., B. Govindasamy, J. P. Iorio, J. Milovich, K. R. Sperber, K. E. Taylor, M. F. Wehner, and S. L. Thompson, 2003: High-resolution simulations of global climate, part 1: Present climate. Climate Dyn., 21, 371-390, doi:10.1007/ s00382-003-0339-z.

Efron, B., and R. Tibshirani, 1993: An Introduction to the Bootstrap. Chapman and Hall/CRC, $450 \mathrm{pp}$.

Feng, Z., L. R. Leung, S. Hagos, R. A. Houze, C. D. Burleyson, and K. Balaguru, 2016: More frequent intense and long-lived storms dominate the springtime trend in central US rainfall. Nat. Commun., 7, 13429, doi:10.1038/ncomms13429.

Findell, K. L., and E. A. B. Eltahir, 2003: Atmospheric controls on soil moisture-boundary layer interactions. Part I: Framework development. J. Hydrometeor., 4, 552-569, doi:10.1175/ 1525-7541(2003)004<0552:ACOSML > 2.0.CO;2.

Flato, G. M., G. J. Boer, W. G. Lee, N. A. McFarlane, D. Ramsden, M. C. Reader, and A. J. Weaver, 2000: The Canadian Centre for Climate Modeling and Analysis global coupled model and its climate. Climate Dyn., 16, 451-467, doi:10.1007/s003820050339.

Fleiss, J. L., 1971: Measuring nominal scale agreement among many raters. Psychol. Bull., 76, 378-382, doi:10.1037/h0031619.

Gensini, V. A., C. Ramseyer, and T. L. Mote, 2014: Future convective environments using NARCCAP. Int. J. Climatol., 34, 1699-1705, doi:10.1002/joc.3769.

Giorgi, F., M. R. Marinucci, and G. T. Bates, 1993a: Development of a second-generation Regional Climate Model (RegCM2). Part I: Boundary-layer and radiative transfer processes. Mon. Wea. Rev., 121, 2794-2813, doi:10.1175/1520-0493(1993)121<2794: DOASGR $>2.0 . C O ; 2$.

$\longrightarrow,-$ - G. de Canio, and G. T. Bates, 1993b: Development of a second-generation Regional Climate Model (RegCM2). Part II: Convective processes and assimilation of lateral boundary conditions. Mon. Wea. Rev., 121, 2814-2832, doi:10.1175/ 1520-0493(1993)121<2814:DOASGR > 2.0.CO;2.

Gordon, C., C. Cooper, C. A. Senior, H. Banks, J. M. Gregory, T. C. Johns, J. F. B. Mitchell, and R. A. Wood, 2000: The simulation of SST, sea ice extents and ocean heat transports in a version of the Hadley Centre coupled model without flux adjustments. Climate Dyn., 16, 147-168, doi:10.1007/s003820050010.

Grell, G. A., J. Dudhia, and D. R. Stauffer, 1993: A description of the Fifth-generation Penn State/NCAR Mesoscale Model (MM5). NCAR Tech. Note NCAR/TN-398+STR, 128 pp., doi:10.5065/D60Z716B.

Guo, Z., and Coauthors, 2006: GLACE: The Global LandAtmosphere Coupling Experiment. Part II: Analysis. J. Hydrometeor., 7, 611-625, doi:10.1175/JHM511.1.

Harding, K. J., and P. K. Snyder, 2014: Examining future changes in the character of Central U.S. warm-season precipitation using dynamical downscaling. J. Geophys. Res. Atmos., 119, 1311613 136, doi:10.1002/2014JD022575.

,$- \ldots$, and S. Leiss, 2013: Use of dynamical downscaling to improve the simulation of Central U.S. warm season precipitation in CMIP5 models. J. Geophys. Res. Atmos., 118, 12 522-12 536, doi:10.1002/2013JD019994.

Held, I. M., and B. J. Soden, 2006: Robust responses of the hydrological cycle to global warming. J. Climate, 19, 5686-5699, doi:10.1175/JCLI3990.1.

Helfand, M. H., and S. D. Schubert, 1995: Climatology of the simulated Great Plains low-level jet and its contribution to the continental moisture budget of the United States. J. Climate, 8, 784-806, doi:10.1175/1520-0442(1995)008<0784:COTSGP > 2.0.CO;2.

Higgins, R. W., Y. Yao, and X. L. Wang, 1997: Influence of the North American monsoon system on the U.S. summer precipitation regime. J. Climate, 10, 2600-2622, doi:10.1175/ 1520-0442(1997)010<2600:IOTNAM >2.0.CO;2.

_ - Y. Chen, and A. V. Douglas, 1999: Interannual variability of the North American warm season precipitation regime. J. Climate, 12, 653-680, doi:10.1175/1520-0442(1999)012<0653: IVOTNA $>2.0 . \mathrm{CO} ; 2$.

Johns, R. H., 1993: Meteorological conditions associated with bow echo development in convective storms. Wea. Forecasting, 8, 294-299, doi:10.1175/1520-0434(1993)008<0294:MCAWBE>2.0.CO;2.

Jones, R. G., D. C. Hassell, D. Hudson, S. S. Wilson, G. J. Jenkins, and J. F. B. Mitchell, 2003: Workbook on generating highresolution climate change scenarios using PRECIS. United Nations Development Programme Rep., 32 pp.

Juang, H. M., S. Y. Hong, and M. Kanamitsu, 1997: The NCEP regional spectral model. An update. Bull. Amer. Meteor. Soc., 78, 2125-2143, doi:10.1175/1520-0477(1997)078<2125: TNRSMA $>2.0 . \mathrm{CO} ; 2$.

Koster, R. D., and Coauthors, 2004: Regions of strong coupling between soil moisture and precipitation. Science, $\mathbf{3 0 5}, 1138-$ 1140, doi:10.1126/science.1100217.

- , and Coauthors, 2006: GLACE: The Global LandAtmosphere Coupling Experiment. Part I: Overview. J. Hydrometeor., 7, 590-610, doi:10.1175/JHM510.1.

Koutsoyiannis, D., A. Efstratiadis, N. Mamassis, and A. Christofides, 2008: On the credibility of climate predictions. Hydrol. Sci. J., 53, 671-684, doi:10.1623/hysj.53.4.671.

Lahmers, T. M. and Coauthors, 2016: Long-term changes in the climatology of transient inverted troughs over the North American monsoon region and their effects on precipitation. J. Climate, 29, 6037-6064, doi:10.1175/JCLI-D-15-0726.1.

Li, W. H., L. F. Li, R. Fu, Y. Deng, and H. Wang, 2011: Changes to the North Atlantic subtropical high and its role in the intensification of summer rainfall variability in the southeastern United States. J. Climate, 24, 1499-1506, doi:10.1175/ 2010JCLI3829.1.

Liang, X. Z., J. Pan, J. Zhu, K. E. Kunkel, J. X. L. Wang, and A. Dai, 2006: Regional climate model downscaling of the U.S. 
summer climate and future change. J. Geophys. Res., 111, D10108, doi:10.1029/2005JD006685.

Mahoney, K., M. Alexander, J. D. Scott, and J. Barsugli, 2013: Highresolution downscaled simulations of warm-season extreme precipitation events in the Colorado front range under past and future climates. J. Climate, 26, 8671-8689, doi:10.1175/JCLI-D-12-00744.1.

Marsh, P. T., H. E. Brooks, and D. J. Karoly, 2007: Assessment of the severe weather environment in North America simulated by a global climate model. Atmos. Sci. Lett., 8, 100-106, doi:10.1002/asl.159.

McCrary, R. R., and D. A. Randall, 2010: Great Plains drought in simulations of the twentieth century. J. Climate, 23, 2178-2196, doi:10.1175/2009JCLI3061.1.

Mearns, L. O., and Coauthors, 2007: The North American Regional Climate Change Assessment Program dataset. National Center for Atmospheric Research Earth System Grid, doi:10.5065/D6RN35ST.

- and Coauthors, 2012: The North American Regional Climate Change Assessment Program: Overview of phase I results. Bull. Amer. Meteor. Soc., 93, 1337-1362, doi:10.1175/ BAMS-D-11-00223.1.

—_, and Coauthors, 2013: Climate change projections of the North American Regional Climate Change Assessment Program (NARCCAP). Climatic Change, 120, 965-975, doi:10.1007/s10584-013-0831-3.

_ - and Coauthors, 2014: Climate Change in North America. Springer, $267 \mathrm{pp}$.

Mesinger, F., and Coauthors, 2006: North American Regional Reanalysis. Bull. Amer. Meteor. Soc., 87, 343-360, doi:10.1175/ BAMS-87-3-343.

Moncrieff, M. W., and C. H. Liu, 2006: Representing convective organization in prediction models by a hybrid strategy. J. Atmos. Sci., 63, 3404-3420, doi:10.1175/JAS3812.1.

Moss, R., and Coauthors, 2008: Towards New Scenarios for Analysis of Emissions. Intergovernmental Panel on Climate Change, $132 \mathrm{pp}$.

Myoung, B., and J. W. Nielsen-Gammon, 2010: The convective instability pathway to warm season drought in Texas. Part I: The role of convective inhibition and its modulation by soil moisture. J. Climate, 23, 4461-4473, doi:10.1175/2010JCLI2946.1.

Nakićenović, N., and Coauthors, 2000: Special Report on Emissions Scenarios. Cambridge University Press, 599 pp.

NCL, 2016: The NCAR Command Language, version 6.3.0. UCAR/NCAR/CISL/TDD, doi:10.5065/D6WD3XH5.

Oleson, K. W., and Coauthors, 2004: Technical description of the Community Land Model (CLM). NCAR Tech. Note NCAR/ TN-461+STR, 186 pp.

— Model and their impact on the hydrological cycle. J. Geophys. Res., 113, G01021, doi:10.1029/2007JG000563.

Pal, J. S., and Coauthors, 2007: Regional climate modeling for the developing world: The ICTP RegCM3 and RegCNET. Bull. Amer. Meteor. Soc., 88, 1395-1409, doi:10.1175/BAMS-88-9-1395.

Patricola, C. M., and K. H. Cook, 2013a: Mid-twenty-first century warm season climate change in the central United States. Part I: Regional and global model predictions. Climate Dyn., 40, 551-568, doi:10.1007/s00382-012-1605-8.

$\longrightarrow$, and,$- 2013 \mathrm{~b}$ : Mid-twenty-first century climate change in the Central United States. Part II: Climate change processes. Climate Dyn., 40, 569-583, doi:10.1007/s00382-012-1379-z.

Pope, V. D., M. L. Gallani, P. R. Rowntree, and R. A. Stratton, 2000: The impact of new physical parameterizations in the Hadley Centre climate model: HadAM3. Climate Dyn., 16, 123-146, doi:10.1007/s003820050009.
Rasmussen, E. N., and D. O. Blanchard, 1998: A baseline climatology of sounding-derived supercell and tornado forecast parameters. Wea. Forecasting, 13, 1148-1164, doi:10.1175/ 1520-0434(1998)013<1148:ABCOSD > 2.0.CO;2.

Roads, J. O., S. C. Chen, A. K. Guetter, and K. P. Georgakakos, 1994: Large-scale aspects of the United States hydrologic cycle. Bull. Amer. Meteor. Soc., 75, 1589-1610, doi:10.1175/ 1520-0477(1994)075<1589:LSAOTU>2.0.CO;2.

Seidel, D. J., Q. Fu, W. J. Randel, and T. J. Reichler, 2008: Widening of the tropical belt in a changing climate. Nat. Geosci., 1, 21-24, doi:10.1038/ngeo.2007.38.

Skamarock, W. C., J. B. Klemp, J. Dudhia, D. O. Gill, D. M. Barker, W. Wang, and J. G. Powers, 2005: A description of the Advanced Research WRF version 2. NCAR Tech. Note NCAR/TN-468+STR, 88 pp.

Tandon, N. F., E. P. Gerber, A. H. Sobel, and L. M. Polvani, 2013: Understanding Hadley cell expansion versus contraction: Insights from simplified models and implications for recent observations. J. Climate, 26, 4304-4321, doi:10.1175/JCLI-D-12-00598.1.

Tawfik, A. B., and P. A. Dirmeyer, 2014: A process-based framework for quantifying the atmospheric preconditioning of surface-triggered convection. Geophys. Res. Lett., 41, 173-178, doi:10.1002/2013GL057984.

Tebaldi, C., J. M. Arblaster, and R. Knutti, 2011: Mapping model agreement on future climate projections. Geophys. Res. Lett., 38, L23701, doi:10.1029/2011GL049863.

Thibeault, J. M., and A. Seth, 2014: A framework for evaluating model credibility for warm-season precipitation in northeastern North America: A case study of CMIP5 simulations and projections. J. Climate, 27, 493-510, doi:10.1175/ JCLI-D-12-00846.1.

Trapp, R. J., N. S. Diffenbaugh, H. E. Brooks, M. E. Baldwin, E. D. Robinson, and J. S. Pal, 2007: Changes in severe thunderstorm environment frequency during the 21 st century caused by anthropogenically enhanced global radiative forcing. Proc. Natl. Acad. Sci. USA, 104, 19719-19723, doi:10.1073/ pnas.0705494104.

Tucker, D. F., and X. Li, 2009: Characteristics of warm season precipitating storms in the Arkansas-Red River basin. J. Geophys. Res., 114, D13108, doi:10.1029/2008JD011093.

Tuttle, J. D., and C. A. Davis, 2006: Corridors of warm season precipitation in the central United States. Mon. Wea. Rev., 134, 2297-2317, doi:10.1175/MWR3188.1.

von Storch, H., and F. W. Zwiers, 1999: Statistical Analysis in Climate Research. Cambridge University Press, 484 pp.

Wang, S. Y., and T. C. Chen, 2009: The late spring maximum of rainfall over the U.S. central plains and the role of the low-level jet. J. Climate, 22, 4696-4709, doi:10.1175/2009JCLI2719.1.

Weaver, S. J., S. Schubert, and H. Wang, 2009: Warm season variations in the low-level circulation and precipitation over the central United States in observations, AMIP simulations, and idealized SST experiments. J. Climate, 22, 5401-5420, doi:10.1175/2009JCLI2984.1.

Wehner, M. F., 2013: Very extreme seasonal precipitation in the NARCCAP ensemble: Model performance and projections. Climate Dyn., 40, 59-80, doi:10.1007/s00382-012-1393-1.

Zhang, G. J., 2002: Convective quasi-equilibrium in midlatitude continental environment and its effect on convective parameterization. J. Geophys. Res., 107, 4220, doi:10.1029/2001JD001005.

_ , and N. A. McFarlane, 1995: Sensitivity of climate simulations to the parameterization of cumulus convection in the Canadian Climate Centre general circulation model. Atmos.-Ocean, 33, 407-446, doi:10.1080/07055900.1995.9649539. 